\title{
Review Article \\ Propolis: A Complex Natural Product with a Plethora of Biological Activities That Can Be Explored for Drug Development
}

\author{
Ricardo Silva-Carvalho,, ${ }^{1,2}$ Fátima Baltazar, ${ }^{1,2}$ and Cristina Almeida-Aguiar ${ }^{3}$ \\ ${ }^{1}$ Life and Health Sciences Research Institute (ICVS), School of Health Sciences, University of Minho, 4710-057 Braga, Portugal \\ ${ }^{2}$ ICVS/3B's, PT Government Associate Laboratory, Guimarães, 4710-057 Braga, Portugal \\ ${ }^{3}$ Centre for the Research and Technology of Agro-Environmental and Biological Sciences (CITAB), Biology Department, \\ University of Minho, 4710-057 Braga, Portugal
}

Correspondence should be addressed to Cristina Almeida-Aguiar; cristina.aguiar@bio.uminho.pt

Received 25 February 2015; Revised 10 May 2015; Accepted 12 May 2015

Academic Editor: Jairo Kennup Bastos

Copyright (C) 2015 Ricardo Silva-Carvalho et al. This is an open access article distributed under the Creative Commons Attribution License, which permits unrestricted use, distribution, and reproduction in any medium, provided the original work is properly cited.

\begin{abstract}
The health industry has always used natural products as a rich, promising, and alternative source of drugs that are used in the health system. Propolis, a natural resinous product known for centuries, is a complex product obtained by honey bees from substances collected from parts of different plants, buds, and exudates in different geographic areas. Propolis has been attracting scientific attention since it has many biological and pharmacological properties, which are related to its chemical composition. Several in vitro and in vivo studies have been performed to characterize and understand the diverse bioactivities of propolis and its isolated compounds, as well as to evaluate and validate its potential. Yet, there is a lack of information concerning clinical effectiveness. The goal of this review is to discuss the potential of propolis for the development of new drugs by presenting published data concerning the chemical composition and the biological properties of this natural compound from different geographic origins.
\end{abstract}

\section{Introduction}

Over the years, nature is continually surprising with diversified natural compounds that can be promising sources for the discovery of new drugs important in medicine [1]. In fact, approximately half of the currently available drugs were obtained from natural compounds or related [2]. The use of natural products as an essential route to new pharmaceutical leads is continually growing and is a research field of enormous interest because the different structural range of natural compounds can provide lead compounds for therapeutic improvement based on rationalized molecular modifications $[3,4]$. It is well known that scientists have curiosity in herbs and other natural plant products for research; however only in the last years the interest in modified plant products by animals, which normally have been largely ignored and wasted, has been increased $[5,6]$.
Propolis, a complex mixture of compounds also called bee glue, is a natural resinous product that honeybees collect from several plants and mix it with beeswax and salivary enzymes ( $\beta$-glucosidase) [7-11]. As inferred for the meaning of the Greek word propolis-pro-, for or in defence, and polis, the city [10]-bees use propolis on their hives as protection against predators and microorganisms, to repair damage, as a thermal isolator, and to build aseptic locals to prevent microbial infection of larvae $[7,9,10,12]$. Since ancient times, propolis has been used by humans to meet the needs of health and food preservation [5]; but only in the last years the interest in this complex natural product has increased due to its broad spectrum of biological and pharmacological properties [12-14]. Propolis is a lipophilic material that is hard and breakable when cold but soft, flexible, and very sticky when warm; it possesses an enjoyable aromatic smell and different coloration, including brown, 
green, and red, among others $[5,7,12]$. In terms of chemical composition, it is generally composed of 50\% resin, 30\% wax, $10 \%$ essential oils, $5 \%$ pollen, and $5 \%$ other substances which include minerals and organic compounds like phenolic acids (cinnamic and caffeic acid) or their esters, flavonoids (flavones, flavanones, flavonols, and dihydroflavonols chalcones), terpenes, aromatic aldehydes and alcohols, fatty acids, stilbenes, and $\beta$-steroids $[8,9]$. Analysis of different samples revealed that propolis chemical composition is difficult to standardize because it depends on different phytogeographic characteristics like vegetation, season, and environmental conditions of the site of collection, as bees select different plants in different habitats for propolis production $[6,8,9]$.

Several in vitro and in vivo studies have been describing the plethora of biological activities and chemical profiles of propolis from different geographic origins. This review highlights published data about such works focusing on the antimicrobial, anti-inflammatory, antioxidant, immunomodulatory, and antitumor activities of different propolis types, in order to unravel the potential of this natural compound for the development of new drugs.

\section{Use of Propolis in Ancient and Current Times}

Propolis is not a new discovery. Since bee's domestication, men explore its products to their own benefit and propolis, one of the most important chemical weapons of bees, is no exception, having been employed extensively since almost immemorial times $[6,13,15-17]$. It is stated that propolis use dates back to ancient times, at least to $300 \mathrm{BC}$, where it was used in folk medicine and other activities in many parts of the world [16]. It was familiar to the Egyptians, in particular by the priests who controlled medicine and chemistry and knew very well propolis antiputrefactive properties. They learned from the bees the embalming capacity of propolis as this natural product is used to perform the mummification of corpses and prevent spread of infections. The Greek and the Roman physicians also acknowledged the potential of propolis by employing it in wound treatment, as an antiseptic and cicatrizing agent, and as mouth disinfectant. The Persians described propolis as a drug capable of acting against eczemas, myalgia, and rheumatism. Populations of the new world, like Incas, also used propolis as an antipyretic agent.

Between the 17th and 20th century, this natural product became very popular in Europe. In 1969, in the former Union of Soviet Socialist Republics (USSR), the use of propolis was accepted in human and veterinary medicine, with several applications including the treatment of tuberculosis, where the regression of lung problems and recovery of appetite were observed. Also, it was believed to cure some diseases in folk Georgian medicine. During World War II (1939-1945), doctors used propolis to treat wounds [15-17], but only in 1985, in Japan, propolis was considered as very promising in pharmacology. Before that, propolis was considered a product without market value, especially because its production is low and affects honey production. Nowadays, propolis is an important product in alternative medicine in Japan, being widely imported from Brazil [18]. In the 17th century, the Italian Antonio Stradivari who is considered the most significant and the greatest crafter of string instruments, like violins, used propolis as an ingredient in the varnish of his instruments. Curiously, such as in the 17th century, propolis is currently used in rosin for stringed instruments and in the repair of accordions [16].

Propolis is one of the few natural products that maintained popularity for a long time, although it is not considered a therapeutic agent in conventional medicine. Actually, it is widely used as a component in pharmaceutical and cosmetic products such as antiacne creams, facial and body creams, ointments and lotions, and several formulations for oral hygiene $[15,16]$. It is also used in some foods and beverages, or simply as food supplement or healthy drinks. This name was attributed to the drinks because it is thought that propolis improves human health and prevents diseases such as heart disease or diabetes, among others [19].

\section{Origin and Composition of Propolis}

Propolis knowledge has registered an important evolution over time, due to exhaustive studies regarding its chemical composition and biological activities. In the $60 \mathrm{~s}$, it was thought that, despite its complexity, propolis chemical composition was more or less constant. Nevertheless, in the following years, analysis of a large number of samples from different geographic origins revealed that chemical composition of propolis is highly variable and also difficult to standardize because it depends on factors such as the vegetation, season, and environmental conditions of the site of collection [6, 8, 9]. Marcucci [7] and Bankova et al. [10] registered more than 300 substances in propolis and recent reports showed the presence of compounds never mentioned before $[12,17,20,21]$.

Generally, the main constituents of propolis are resin and volatiles, which are substances obtained from a variety of botanical processes in different parts of plants, and beeswax, secreted by the bees [9]. Typical compounds are summarized in Table 1. As can be seen, plant sources vary among the different parts of the globe, leading to panoply of compounds. In a review on propolis standardization, different resin types were proposed: poplar propolis, birch, green, red, "Pacific," and "Canarian" $[9,12]$. Samples of poplar propolis (e.g., from Europe, North America, New Zealand, and temperate zones of Asia) are mainly composed of flavonoids, phenolic acids, and their esters [10, 20, 22], clearly different from other propolis types (Table 1). Portuguese propolis, despite similar to the ones found in European samples, also contains new methylated, esterified, and hydroxylated derivatives of flavonoids and pinocembrin/pinobanksin derivatives containing a phenylpropanoic acid derivative moiety in their structure [20, 21]. Our group recently showed that propolis from Pereiro (district of Guarda, Beira Alta) (Figure 1) has a high concentration of phenolic components [23].

Poplar-type propolis is undoubtedly the most studied one but there are many other propolis types. Recent studies have revealed a new type of European propolis: Mediterranean propolis. This type of propolis is distinguished by the high 


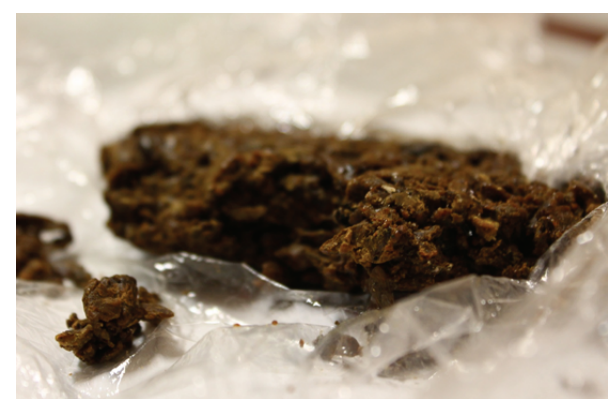

Figure 1: Crude sample of propolis from Pereiro, obtained in the central region of Portugal (Guarda). The sample was kindly supplied by Engineer Pedro Fernandes (Mel do Abel).

concentration of diterpenoids and is found in many regions like Greece [24, 25], Switzerland [26], Malta [27], Turkey [28$30]$, or Algeria [28, 31].

Propolis from tropic regions, like Brazil, Cuba, Venezuela, and Chile, has been attracting much attention in the last years due to its particular chemical profiles. Prenylated phenylpropanoids, prenylated $p$-coumaric acids, acetophenones, diterpenic acids, and caffeoylquinic acids were shown to be very common and abundant in propolis from Brazil, mainly from the south-eastern region $[9,10,21]$. The flavonoids kaempferide and isosakuranetin and some amounts of kaempferol were also found in Brazilian samples [32]. Additionally, red propolis from the northeast regions of Brazil presents high concentrations of phenolic acids and the flavonoids formononetin, isoliquiritigenin, liquiritigenin, medicarpin, and biochanin A [33-35]. Cuban propolis has a peculiar enrichment in polyisoprenylated benzophenones, more specifically nemorosone, and a minor content of a mixture of xanthochymol and guttiferone $\mathrm{E}[9,36]$ making this type of sample chemically distinct from both European and Brazilian propolis. Propolis from Venezuela is also composed of polyisoprenylated benzophenones in addition to the usual constituents found in samples of tropical regions $[9,37,38]$.

Information about the chemical composition of Australian propolis is very limited despite the great biodiversity of the island. Propolis from Kangaroo Island is mainly composed of stilbenes, some of them being prenylated. Additionally, it has also some prenylated cinnamic acids and flavonoids [39], like $2^{\prime}, 3^{\prime}, 4^{\prime}$-trimethoxychalcone, 2' -hydroxy- $3^{\prime}, 4^{\prime}$-dimethoxychalcone, $2^{\prime}, 4^{\prime}$-dihydroxy- $3^{\prime}$-methoxychalcone, 5,7-dihydroxy-2,3-dihydroflavonol 3-acetate (pinobanksin 3-acetate), and 5,7-dihydroxy-6-methoxy-2,3dihydroflavonol 3-acetate [40]. Western Australian propolis is composed of Xanthorrhoeol, pterostilbene, sakuranetin, and pinostrobin [41]. Propolis of Australian stingless bees (Tetragonula carbonaria) is composed of C-methylated flavanones [42].

"Pacific" propolis (e.g., Okinawa, Taiwan, Hawaii, Indonesia, and Myanmar) is another particular type of propolis. A new family of compounds, the prenylflavonoids, more specifically isonymphaeol-B, was identified in Okinawa propolis although three already known compounds-nymphaeol-A, nymphaeol-B, and nymphaeol-C-have also been isolated in three samples [43]. As Okinawan propolis, Hawaiian propolis is also composed of nine prenylflavonoids [44]. Taiwanese propolis is composed of eight prenylflavanones, nymphaeol-A, nymphaeol-B, and nymphaeol-C, propolins $\mathrm{A}, \mathrm{B}$, and $\mathrm{E}$, isonymphaeol $\mathrm{B}$, and $3^{\prime}$-geranylnaringenin [45]. In another sample of the Pacific region, the Indonesian propolis, an inseparable mixture of four alk(en)ylresorcinols (5-pentadecylresorcinol, 5- $\left(8^{\prime} Z, 11^{\prime} Z\right.$ heptadecadienyl)-resorcinol, 5-(11'Z-heptadecenyl)-resorcinol, and 5-heptadecylresorcinol), along with four prenylflavanones, propolins $\mathrm{D}, \mathrm{C}, \mathrm{F}$, and $\mathrm{G}$, and three cycloartanetype triterpenes, mangiferolic acid, isomangiferolic acid, and 27-hydroxyisomangiferolic acid, was identified [46]. Additionally, fractioning of propolis extracts from Myanmar led to the isolation of two new cycloartane-type triterpenes, together with 13 cycloartanes and four known prenylated flavanones [47]. Thailand propolis, which might be possibly obtained from Styrax trees, comprises not only the typical compounds of temperate regions but also the two new phenylallylflavanones $\left(7^{\prime \prime} S\right)-8-\left[1-\left(4^{\prime}\right.\right.$-hydroxy- $3^{\prime}$ methoxyphenyl)prop-2-en-1-yl]-(2S)-pinocembrin and (E)cinnamyl-(E)-cinnamylidenate [48]. In propolis from Canary Islands, a different phenolic profile was found, furofuran lignans being the main compounds. Six furofuran lignans were isolated and characterized as sesamin, episesamin, methyl xanthoxylol, aschantin, sesartenin, and yangambin. Propolis also contains sugars and sugar alcohols [10, 49]. Many studies with African propolis from different regions, like Kenya, Cameroon, Congo, Oman, and Ethiopia, showed that triterpenoids are major chemical components [50-53]. Southern Nigeria propolis is uncommon since it presents prenylated isoflavonoids, like Brazilian red propolis, and a high abundance of stilbenoid compounds [54].

Propolis additionally contains minerals such as magnesium, calcium, iodine, potassium, sodium, copper, zinc, manganese, and iron; some vitamins like B1, B2, B6, C, $\mathrm{E}$, and $\mathrm{D}$, as well as provitamin $\mathrm{A}$; a few fatty acids; and also some enzymes derived from bee glandular secretion or possibly from pollen like succinic dehydrogenase, adenosine triphosphatase, glucose-6-phosphatase, acid phosphatase, $\alpha$-amylase, $\beta$-amylase, $\alpha$-lactamase, $\beta$-lactamase, maltase, esterase, and transhydrogenase $[17,55]$. Polysaccharides like starch and the di- and monosaccharaides glucose, fructose, ribose, rhamnose, talose, gulose, and saccharose are commonly present in propolis too [55].

\section{Biological Properties and Therapeutic Activity of Propolis}

Despite propolis popularity over time, it is not considered as a therapeutic agent in conventional medicine as the standardization of chemical composition and biological activity is lacking. Such standardization is indispensable for acceptance in the health system. Thus, characterization of different types of propolis according to its plant origin and corresponding chemical profile is mandatory. Studies about propolis bioactivity must start with chemical profiling of the extracts since that information is essential to have detailed and consistent comparative data between each type 


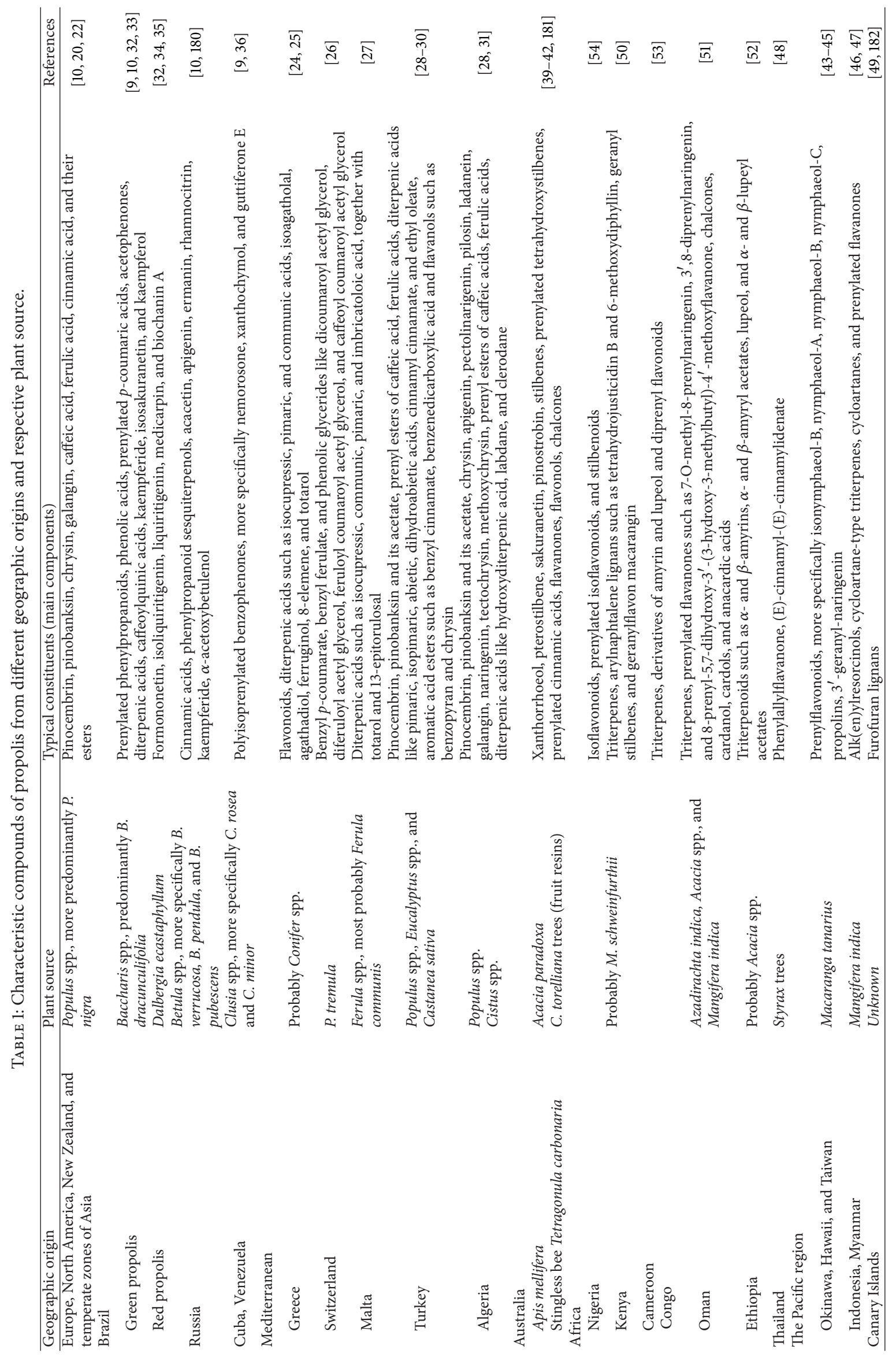


of biological activity and chemical data. This information allows extrapolating the possible activity and mechanism of action of new propolis under study and provides substantial clues for the development of new drug candidates $[6,9]$.

In the last decades, several studies have demonstrated the biological and pharmacological actions of different worldwide propolis samples. The following sections summarize the recent published information about antibacterial and antifungal $[6,7,56-59]$, antiviral $[7,59,60]$, anti-inflammatory [61], antioxidant [62-64], immunomodulatory [6, 65, 66], and antitumor activities $[8,17,23,64,66,67]$, revealing the interest of researchers in this bee product and its potential for the development of new drugs as well.

4.1. Antioxidant Activity. It is well known that an endogenous stimuli, like cellular metabolism, and exogenous agents like UV, toxins, and drugs, among others, generate reactive oxygen species (ROS), such as hydrogen peroxide $\left(\mathrm{H}_{2} \mathrm{O}_{2}\right)$, the superoxide anion $\left(\mathrm{O}_{2}{ }^{-}\right)$, and hydroxyl ion $\left(\mathrm{HO}^{-}\right)$, as well as reactive nitrogen species (RNS), especially nitric oxide (NO). Carbohydrates, proteins, lipids, and nucleic acids, among other biomolecules, when exposed to the reactive species, suffer oxidative modifications that modify the cell and lead to its death [68-70]. Oxidative stress is responsible for the occurrence of a wide variety of human diseases, such as neurodegenerative [71] or cardiovascular diseases [72, 73], cancer $[68,74]$, diabetes [6], and atherosclerosis [75].

In the last years, several studies have been performed to evaluate the antioxidant capacity of natural products. Propolis extracts, composed of different polyphenols, have been reported to possess a potent antioxidant activity [70, 76, 77]. Additionally, the chemical varieties in different propolis samples from different regions have an influence on the antioxidant activity. Recently, Fabris et al. showed that a sample of Italian and Russian propolis ethanol extract (PEE), which have a similar polyphenolic composition, have a similar antioxidant activity, while Brazilian PEE, which have low polyphenolic composition, have a weak antioxidant activity [78]. Another study also showed, using different samples of Transylvania PEE, a positive correlation between high polyphenolic composition and high antioxidant activity [79]. Phenolic acids and flavonoids are characterized by a powerful antioxidant activity, which is closely related to the chemical structure of the compounds [80]. Briefly, the antioxidant activity is exerted by inhibiting the activity of some enzymes (e.g., xanthine oxidase, protein kinase C, ascorbic acid oxidase, cyclooxygenase, lipoxygenase, $\mathrm{Na}^{+} / \mathrm{K}^{+}$ ATPase, and cAMP phosphodiesterase) which inhibit the production of ROS species; by scavenging, interrupting the reactions that lead to the lipid peroxidation; by chelating metal ions, mainly iron and copper, that are involved in the process of free radical creation; or by potentiating the action of other antioxidants [55]. Table 2 summarizes some of the studies addressing the antioxidant activity of propolis.

Moreira et al. [62] and Miguel et al. [63] proposed that Portuguese propolis, an important source of total phenols, flavones, and flavonols, could be beneficial for human health due to its antioxidant properties. Portuguese propolis also protects human erythrocytes from free radicals damaging by decreasing lipid peroxidation [64]. These studies suggest that Portuguese propolis is a powerful antioxidant agent that can be used against oxidative stress, thus maintaining the structural and functional integrity of the cells. CuestaRubio et al. [36] demonstrated that nemorosone, the most abundant polyisoprenylated benzophenone present in Cuban propolis, exhibits antioxidant capacity. However, when this compound suffers methylation, a process that facilitates the separation of the compound from the propolis sample, the antioxidant property is abolished. Ethyl acetate extract of Kangaroo Island propolis, which is rich in stilbenes, showed a stronger scavenging activity [39]. Yang et al. showed that ethyl acetate of propolis collected in Anhui, China, has strong scavenging activity and ferric reducing activity, those activities being influenced by caffeic acid, phenethyl caffeate, cinnamyl caffeate, and benzyl caffeate [81]. Another study showed that samples of methanolic extracts of Algerian propolis that contains high amounts of caffeic acid esters and flavanones, kaempferol, and galangin possess strong scavenging activity and ferric reducing activity [31]. Uruguay propolis with high polyphenolic composition inhibits lowdensity lipoprotein (LDL) peroxidation and protein nitration in vitro. Moreover, it induces the expression of nitric oxide synthase (eNOS) and inhibits NADPH oxidase in bovine aortic endothelial cells [82]. In another study, the topical administration of Romanian PEE in mouse, either prior to or after UVB exposure, significantly attenuated the malondialdehyde (MDA) formation and restored glutathione peroxidase (GSH-Px) activity [83]. Talas et al. [84] showed that Turkish PEE has antioxidant properties in the liver tissue of NOS inhibited rats. In fact, NOS inhibition caused an increase in CAT activity and MDA levels, effect that was significantly decreased when the rats were treated with PEE. It is well known that propolis composition is variable; nevertheless, one of its major components, CAPE (caffeic acid phenethyl ester), plays an important role in the antioxidant activity [85-87].

Antioxidant activity is one of the most studied and important activities of propolis, though there are no studies with data on the safe dose to be used in humans. Thus, clinical studies using propolis and its active compounds are needed.

4.2. Anti-Inflammatory Activity. Inflammation is an event that normally occurs in response to the constant exposure to environmental and endogenous stimuli as well as to accidental damage [61]. A complex cascade of chemical signals initiates after tissue injury and maintains a host response to repair the injured tissue. There are two stages of inflammation: acute and chronic. Acute inflammation is mediated through the activation of the immune system cells, which migrate to the site of damage and release growth factors, cytokines, and ROS/RNS species. Chronic inflammation occurs when the acute inflammation is not successfully resolved. This inflammatory condition plays a critical role in the pathogenesis of many diseases including atherosclerosis, cancer, asthma, Alzheimer's, and Parkinsonism [88, 89].

Several studies have associated different types of propolis and its various constituents with anti-inflammatory activity [61, 90-95]. Table 3 summarizes the anti-inflammatory 


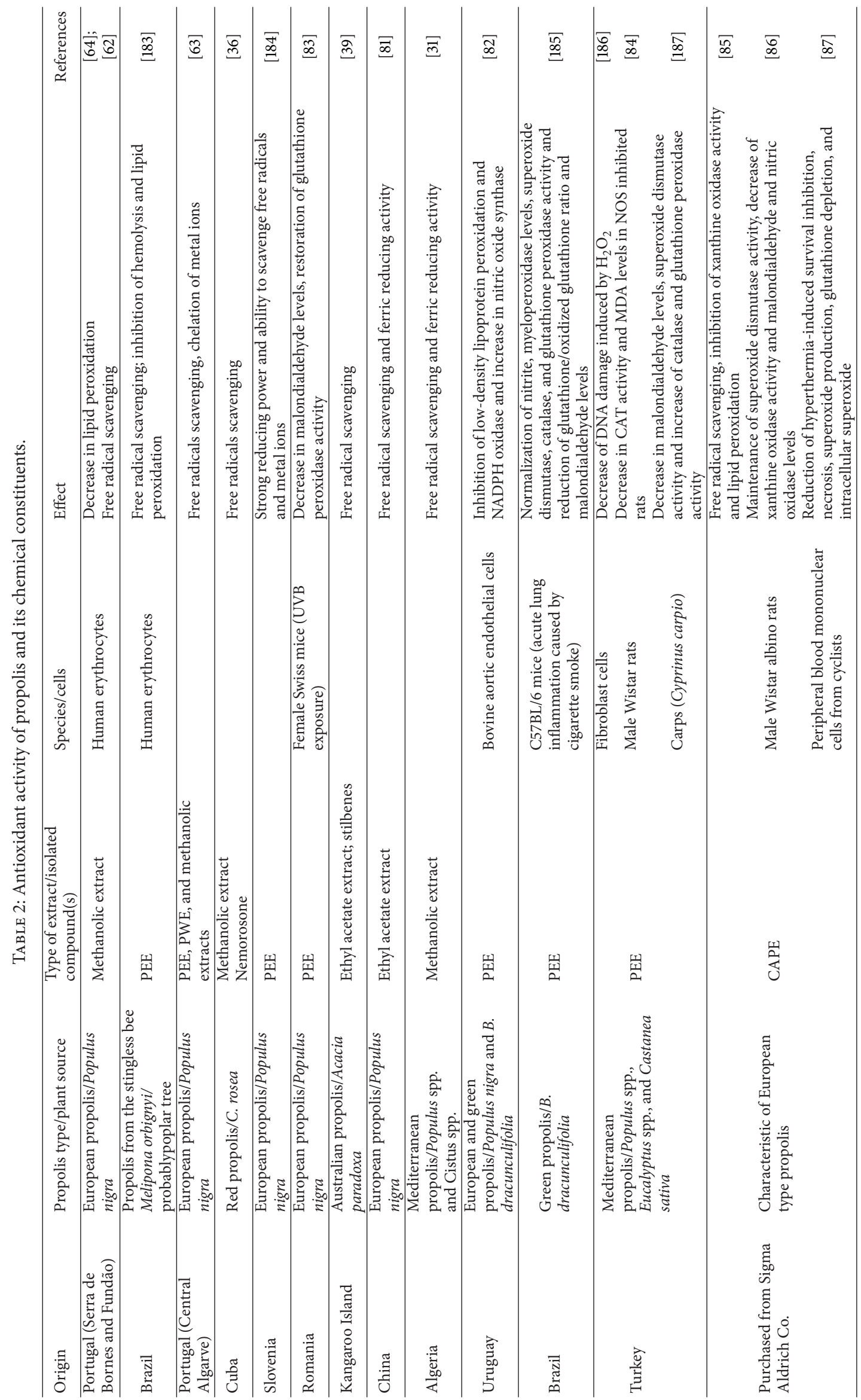




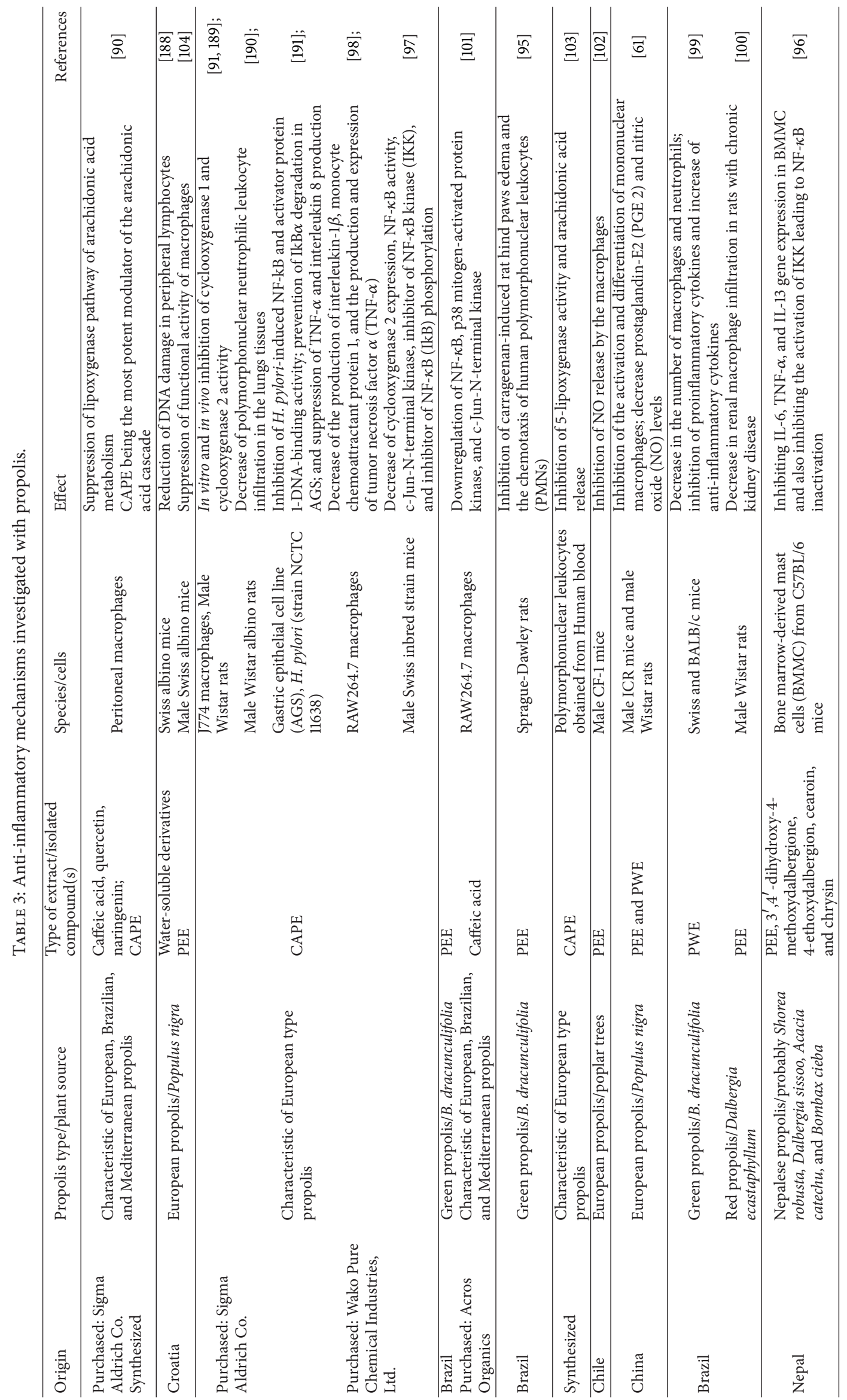


mechanisms investigated with propolis and its chemical constituents. Recently, the role of the flavonoids quercetin, flavonols, and flavones in modulating inflammatory cell function was studied [92]. Funakoshi-Tago et al. [96] investigated the anti-inflammatory effects of flavonoids isolated from Nepalese PEE on the IL-33 signaling pathway. The isolated flavonoids $3^{\prime}, 4^{\prime}$-dihydroxy-4-methoxydalbergione, 4-methoxydalbergion, cearoin, and chrysin inhibited the expression of inflammatory genes including IL-6, TNF- $\alpha$, and IL-13 in bone marrow-derived mast cells (BMMC) and also inhibited the activation of IKK, which leads to the degradation of $\mathrm{I} \kappa \mathrm{B} \alpha$ and inhibits the activation of nuclear factor $\kappa \mathrm{B}(\mathrm{NF}-\kappa \mathrm{B})$.

The release and oxygenation of arachidonic acid are a critical event in inflammation. Mirzoeva and Calder [90] demonstrated that propolis components such as CAPE, caffeic acid, quercetin, and naringenin, among others, inhibit the production of eicosanoids. In fact, these components significantly suppressed the lipoxygenase pathway of arachidonic acid metabolism, CAPE being the most potent modulator. Another study indicated that CAPE treatment improves hepatic steatosis induced by high-fat diet in a mouse model. This effect was attributed to the reduction of c-Jun-Nterminal kinase (JNK1/2) and NF- $\kappa$ B activation with decrease in COX-2 expression [97]. Recently, it was reported that CAPE exhibits inhibitory effects on the production of proinflammatory cytokines (interleukin-1 $\beta$ (IL-1 $\beta)$ ), tumor necrosis factor- $\alpha$ (TNF- $\alpha$ ), and monocyte chemoattractant protein 1 (MCP-1) from lipopolysaccharide- (LPS-) stimulated RAW264.7 macrophages [98]. Machado et al. [99] showed that Brazilian green propolis water extracts (PWE) modulate an anti-inflammatory cellular response in the model of LPSinduced pulmonary inflammation by decreasing the number of macrophages and neutrophils. Additionally, it induced a reduction in the secretion of IL- 6 and TNF- $\alpha$ and an increase in TGF- $\beta$ and IL-10. Another study showed that Brazilian red PEE promotes a significant decrease in renal macrophage infiltration in rats with chronic kidney disease [100]. Búfalo et al. [101] demonstrated that Brazilian PEE and caffeic acid inhibited LPS-induced NO production by RAW264.7 macrophages, acting at the transcriptional level and suggesting that their anti-inflammatory effects were mediated by downregulating NF- $\kappa \mathrm{B}$, p38 MAP kinase, and JNK1/2. According to Naito et al. [95], topical application of Brazilian PEE is effective in inhibiting carrageenan-induced rat hind paw edema. This sample appears to inhibit the chemotaxis of human polymorphonuclear leukocytes (PMNs), which also contributes to its anti-inflammatory effects. Another study showed the topical anti-inflammatory activity of propolis from Chile in mice ear with induced-edema. In fact, PEE from Buin, Chile, was the most active against the inflammation induced by 12-O-tetradeca-noylphorbol-13-acetate and arachidonic acid and also inhibits significantly NO release by the macrophages [102]. More recently, Boudreau et al. [103] indicated that CAPE is a potent leukotriene biosynthesis inhibitor in PMNs that blocks 5-lipoxygenase (5-LO) activity and arachidonic acid release. A Croatian PEE may improve psoriatic-like skin lesions, which were induced in the study by irritant agents like n-hexyl salicylate or di-n-propyl disulfide, by reducing the lipid peroxidation in the skin and total number of inflammatory cells in the skin and peritoneal cavity, more specially by suppressing functional activity of macrophages [104].

4.3. Immunomodulatory Activity. Natural substances are considered alternative adjuvant therapies in the treatment of different diseases due to their immunomodulatory effects. Information about this type of activity was scarce for propolis until the 1990s; but published work in the last years has provided information about the influence of different propolis samples on the immune system [65, 105-112] (Table 4).

In a study using Brazilian green propolis, it was seen that the administration for 3 days of a PEE to male BALB/c mice modulated the activation of the initial steps of the immune response by upregulating toll-like receptor- (TLR-) 2 and toll-like receptor-4 expression and proinflammatory cytokines (IL-1 and IL-6) production by macrophages and spleen cells [105]. Another study demonstrated that Brazilian green PEE upregulates TLR- 4 and CD80 expression in human monocytes as well as TNF- $\alpha$ and IL-10 production [113]. It was also shown that caffeic acid stimulates the activity of monocytes against C. albicans but it inhibits TLR-2 and HLADR expression as well as TNF- $\alpha$ and IL-10 production [114].

Additionally, Missima et al. [115] showed that Brazilian green PEE administered to stressed mice reduces the proinflammatory cytokines IL- $1 \beta$ and IL- 6 . When administered to melanoma-bearing mice submitted or not to chronic stress, it induces high levels of IL-1 $\beta$ and IL- 6 and also stimulates Th1 cytokines production, indicating the activation of antitumour cell-mediated immunity. Bachiega et al. [116] investigated the immunomodulatory effect of propolis and cinnamic and coumaric acids on cytokines IL- $1 \beta$, IL-6, and IL-10 production. Peritoneal macrophages from $B A L B / c$ mice were incubated with different concentrations of propolis (5, 50, and $100 \mathrm{mg} / \mathrm{well})$ and coumaric and cinnamic acid (50 and $100 \mathrm{mg} /$ well). Propolis and the acids stimulated IL$1 \beta$ production and significantly inhibited IL- 6 production. Then, after LPS incubation, the inhibitory concentrations of cinnamic and coumaric acids prevented efficiently its effects on IL-6 production, whereas propolis inhibited LPS effects both before and after its addition. Additionally, propolis and coumaric and cinnamic acids inhibited IL-10 production. A study which evaluated the effect of Brazilian green propolis on macrophage activation by $\mathrm{H}_{2} \mathrm{O}_{2}$ and $\mathrm{NO}$ metabolite determination [107] showed that propolis increased $\mathrm{H}_{2} \mathrm{O}_{2}$ generation and decreased NO generation, which favours the microbicidal activity. Recently, the immunomodulatory effect of propolis collected in Brazil was evaluated in Leishmania (Viannia) braziliensis experimental infection. Data shows that macrophages incubated with propolis showed a significant increase in interiorization and further killing of parasites. Also, an increased TNF- $\alpha$ production was seen in propolis-pretreated mice, whereas IL-12 was downregulated during the infection [117].

The immunomodulatory action of propolis does not occur only at the macrophage level. In fact, some studies show that this action has also an effect on lymphocyte proliferation $[106,108]$. Sá-Nunes et al. [108] showed inhibitory 


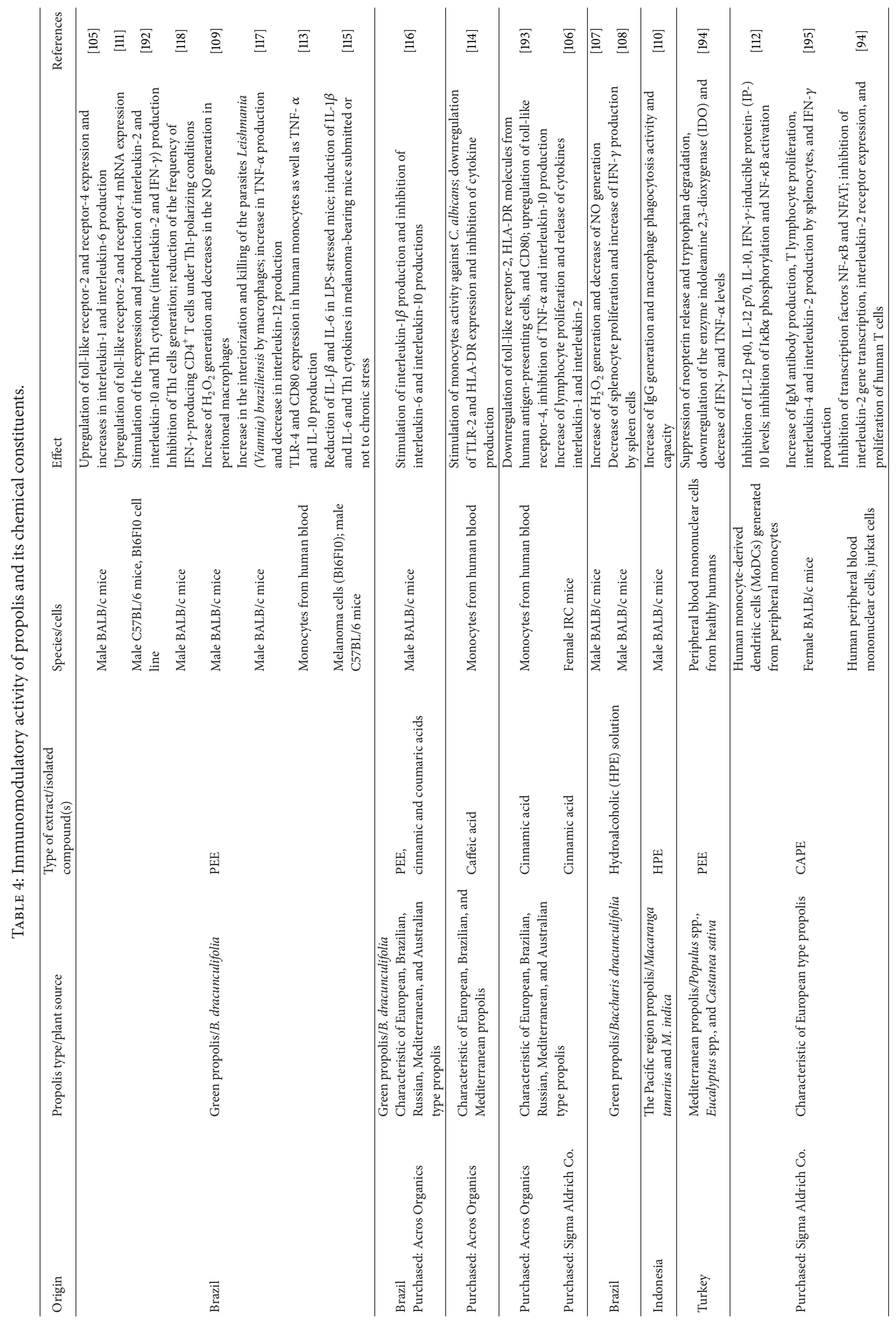


effects of Brazilian green propolis on splenocyte proliferation, effect that was attributed to flavonoids, and enhancement effects on interferon- (IFN-) $\gamma$ production by spleen cells. CAPE displays inhibitory effects on transcription factors NF$\kappa \mathrm{B}$ and NFAT and, as a consequence, inhibits IL-2 gene transcription, IL-2 receptor expression, and proliferation of human T cells [94]. This provides new information into the molecular mechanisms involved in the anti-inflammatory and immunomodulatory activities of propolis. CAPE has various biological activities but its effect on the immunomodulatory activity remains little studied. According to Wang et al. [112], CAPE can be useful in the treatment of asthma and other allergic diseases because it can inhibit cytokines and chemokines production by human monocyte-derived dendritic cells (MoDCs), which might be related to the $\mathrm{NF}-\kappa \mathrm{B}$ signalling pathway. Another study demonstrated for the first time that Brazilian propolis significantly inhibited the generation of Th1 cells. Furthermore, the effects of propolis were investigated on 2,4,6-trinitrobenzene sulfonic acid- (TNBS-) induced colitis in a mouse model. Propolis reduced the frequency of IFN- $\gamma$-producing CD4 T cells in a dose-dependent way under Th1-polarizing conditions. The inhibitory effect of propolis on Th1 differentiation was demonstrated in vivo too, and the severity of colitis in propolis-fed mice was significantly lower than that of mice fed with the control diet [118].

4.4. Antiviral Activity. Propolis comprises a complexity of compounds which play a role in antiviral protection. Despite the few data available regarding this activity, it was shown that propolis from different geographic regions has considerable antiviral activity by acting at different levels and interfering with the replication of some viruses [12], like herpes simplex types 1 and 2, adenovirus type 2, influenza virus, or human immunodeficiency virus (HIV), among others [7, 60, 119124]. Table 5 summarizes the antiviral activity of propolis and its chemical constituents.

Schnitzler et al. [123] analysed the antiviral effect of PWE and PEE from Czech Republic as well as that of the constituents caffeic acid, $p$-coumaric acid, benzoic acid, galangin, pinocembrin, and chrysin, against herpes simplex virus type 1 (HSV-1) in cell culture. Both extracts exhibited high anti-HSV-1 activity when cells were treated prior to viral infection, galangin and chrysin being the main bioactive compounds. Amoros et al. [60] showed the antiviral activity of the major flavonoids of propolis, more specifically flavonols and flavones, the first being more active against HSV-1. Additionally, they analysed the effect of propolis on several DNA and RNA viruses (HSV-1, HSV-2, adenovirus type 2, vesicular stomatitis virus (VSV), and poliovirus type 2). Propolis at a concentration of $30 \mu \mathrm{g} / \mathrm{mL}$ reduced the titer of herpes virus; however, vesicular stomatitis virus and adenovirus were less susceptible. In addition, propolis appears to exert a virucidal action on the enveloped viruses HSV and VSV [120]. Recently, it was shown that hydromethanolic extract of geopropolis from the stingless bee Scaptotrigona postica (Brazil) inhibits the HSV replication and also the entry of the virus into cells, effect that was attributed to the C-glycosyl flavones, catechin-3-O-gallate, and 3,4-dicaffeoylquinic acid [125]. According to Tait et al. [126], natural and synthetic flavonoids might interfere with picornavirus replication preventing the decapsidation of viral particles and RNA release within cells or blocking viral RNA synthesis. These authors also showed that different homoisoflavonoids have good antiviral activity against the coxsackie viruses B3, B4, and A9 and echovirus 30 . Shvarzbeyn and Huleihel [127] tried to determine which step of Tax oncoprotein-induced NF- $\kappa$ B activation is blocked by propolis and CAPE and showed that both substantially inhibited the activation of NF- $\kappa \mathrm{B}$-dependent promoter by Tax. Also, they strongly prevented both Tax binding to $\mathrm{I} \kappa \mathrm{B} \alpha$ and its induced degradation by Tax. Ma et al. [128] showed that nanometer propolis flavones could significantly inhibit in vitro porcine parvovirus (PPV) infecting PK-15 cells and in vivo they restrain the PPV copy in lung, gonad, and blood, decrease the impact of PPV on weight of guinea pigs, and increase hemagglutination inhibition of PPV in serum as well as improving the contents of IL-2, IL-6, and $\gamma$-IFN.

Over recent years, therapeutic benefits of propolis and/or its isolated compounds have been described in HIV treatment. Ito et al. [129] tested the anti-HIV activity in $\mathrm{H} 9$ lymphocytes of triterpenoids melliferone, moronic acid, anwuweizonic acid, and betulonic acid and four known aromatic compounds isolated from Brazilian propolis and showed that moronic acid had significant anti-HIV activity. Gekker et al. [119] assessed the anti-HIV-1 activity of propolis in $\mathrm{CD}^{+}$lymphocytes and microglial cell cultures, observing the inhibition of viral expression in a concentrationdependent way. The possible mechanism of propolis antiviral property was suggested to involve inhibition of viral entry.

4.5. Antimicrobial Activity. Antimicrobial activity, one of the most studied propolis biological properties, is very well documented. This bioactivity has been largely investigated in the last years due to the need of new treatments against infectious diseases, especially with the increase of resistant pathogens to current antibiotics. Tables 6 and 7 summarise the antibacterial and antifungal activities found in propolis from different geographic origin and/or its chemical constituents.

4.5.1. Antibacterial Activity. Propolis effect against several bacterial strains has evaluated $[7,56-59,130]$ and supported the fact that propolis is more active against Gram-positive bacteria than Gram-negative bacteria [12, 59]. Briefly, data from different studies showed that propolis inhibits bacterial motility and enzyme activity, exhibits bacteriostatic activity against different bacterial genera, can be bactericidal in high concentrations, and affects cytoplasmic membrane [130].

Mirzoeva et al. [130] investigated the effect of PEE on the physiology of Bacillus subtilis, Escherichia coli, and Rhodobacter sphaeroides, proposing that propolis and some of its components, like cinnamic acid and flavonoids, affect the ion permeability of the inner bacterial membrane causing the dissipation of the membrane potential and inhibiting bacterial motility. A recent study [131] provided valuable information for understanding the potential anti-H. pylori 


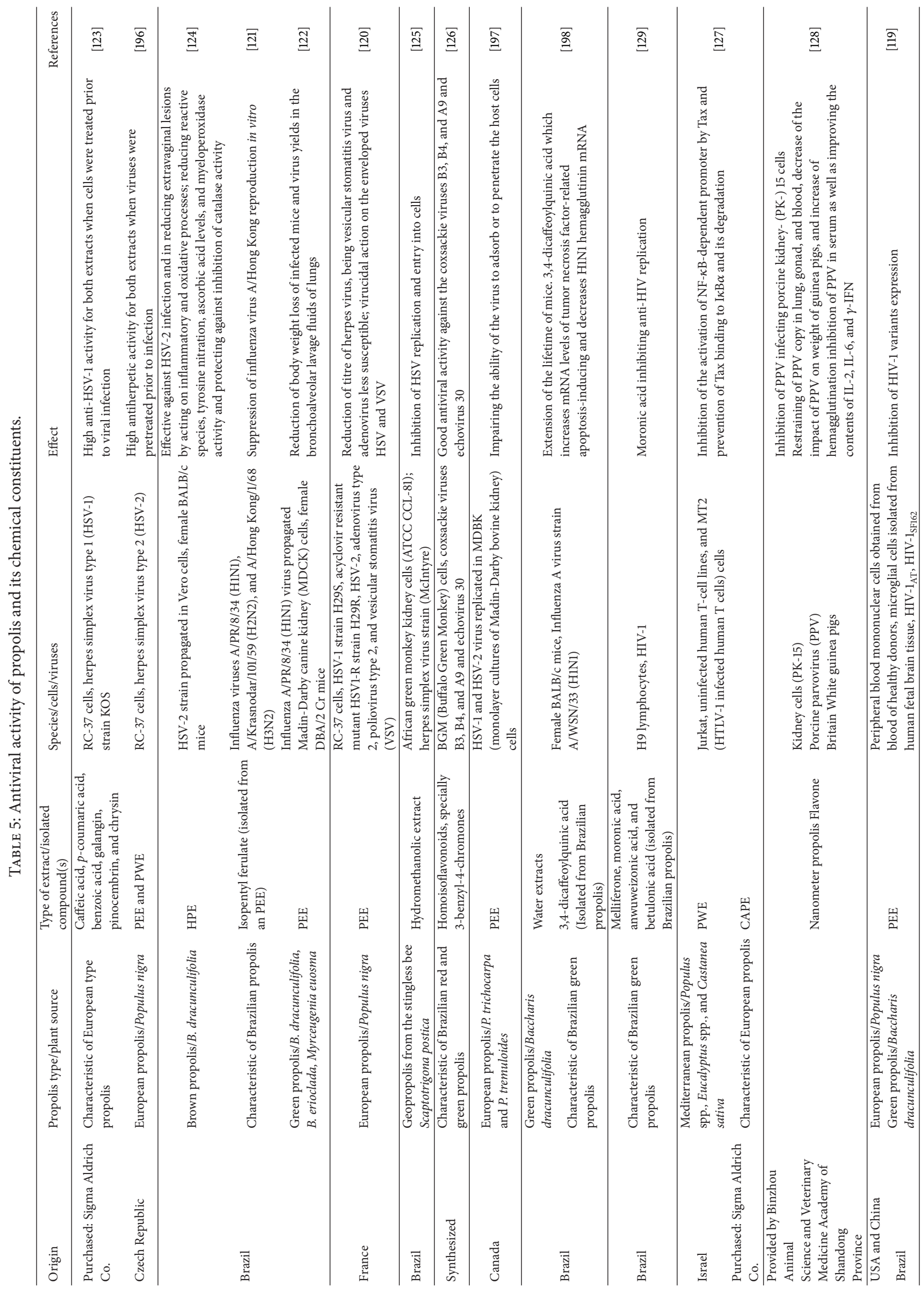




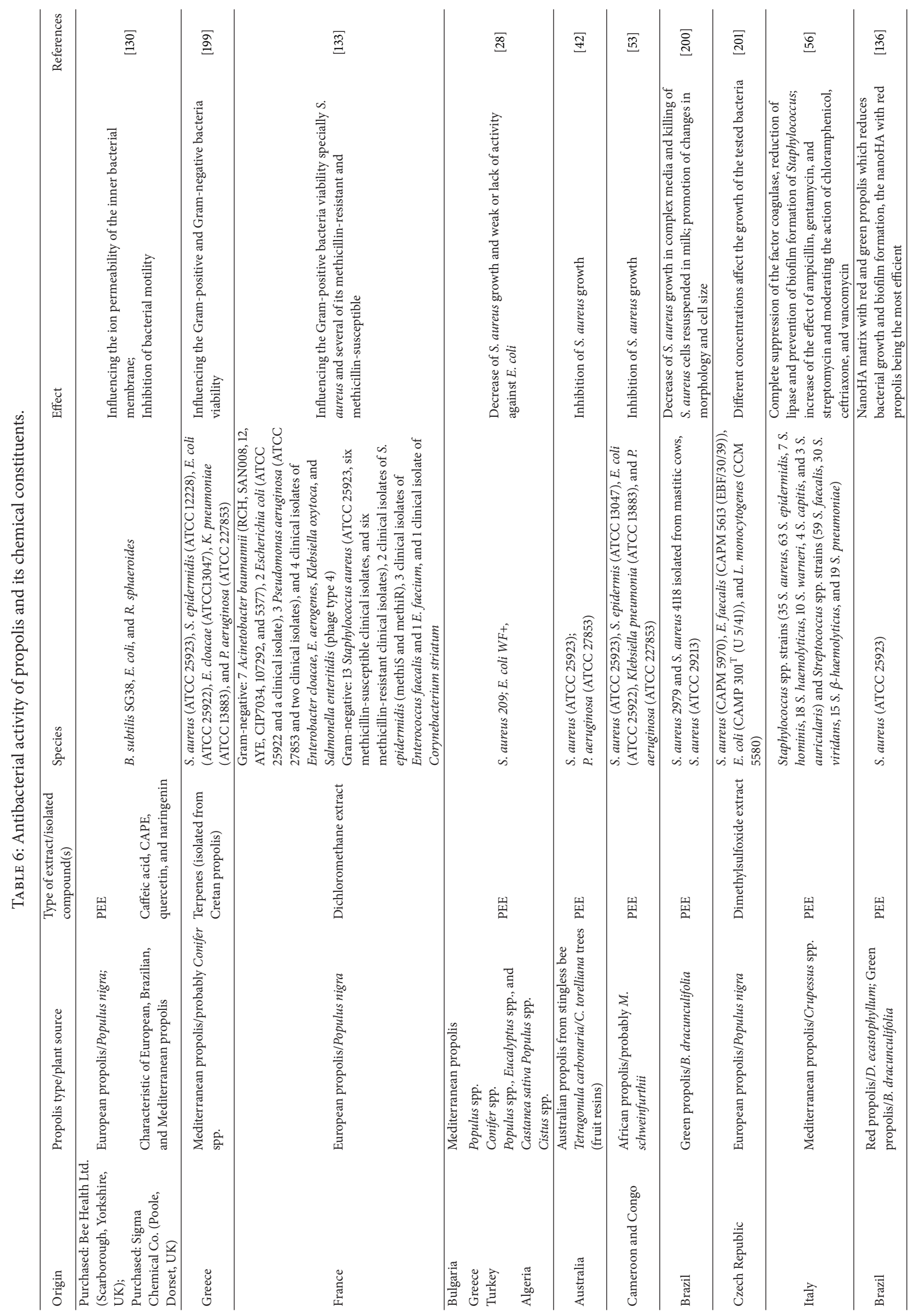




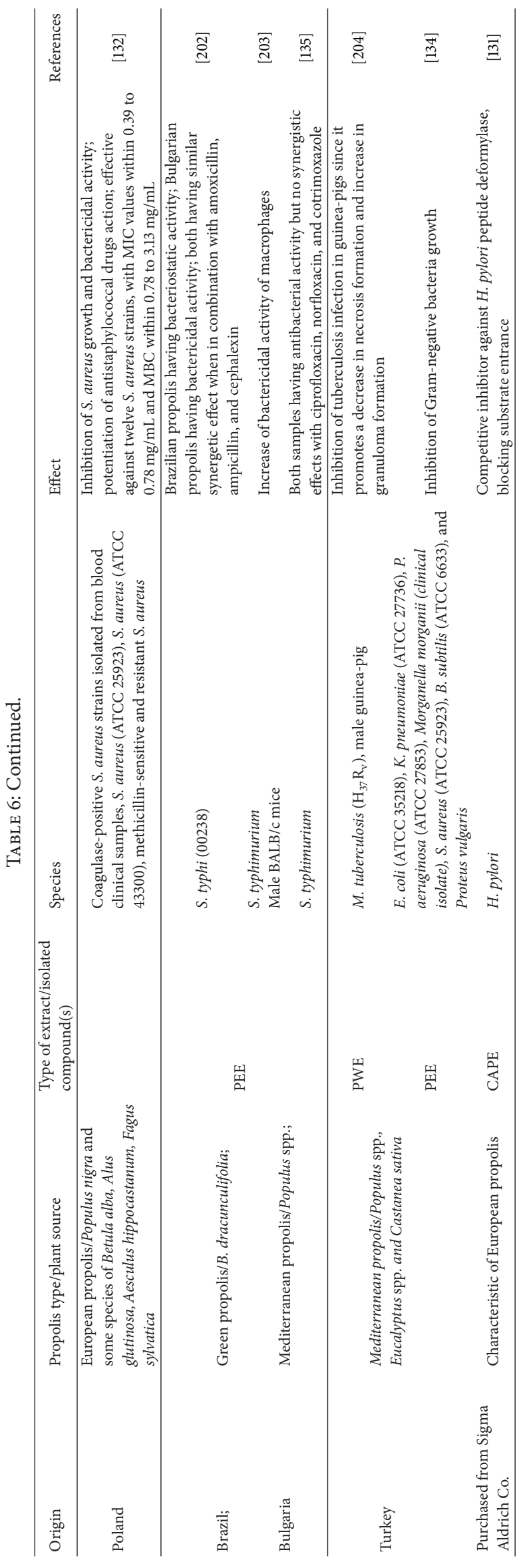




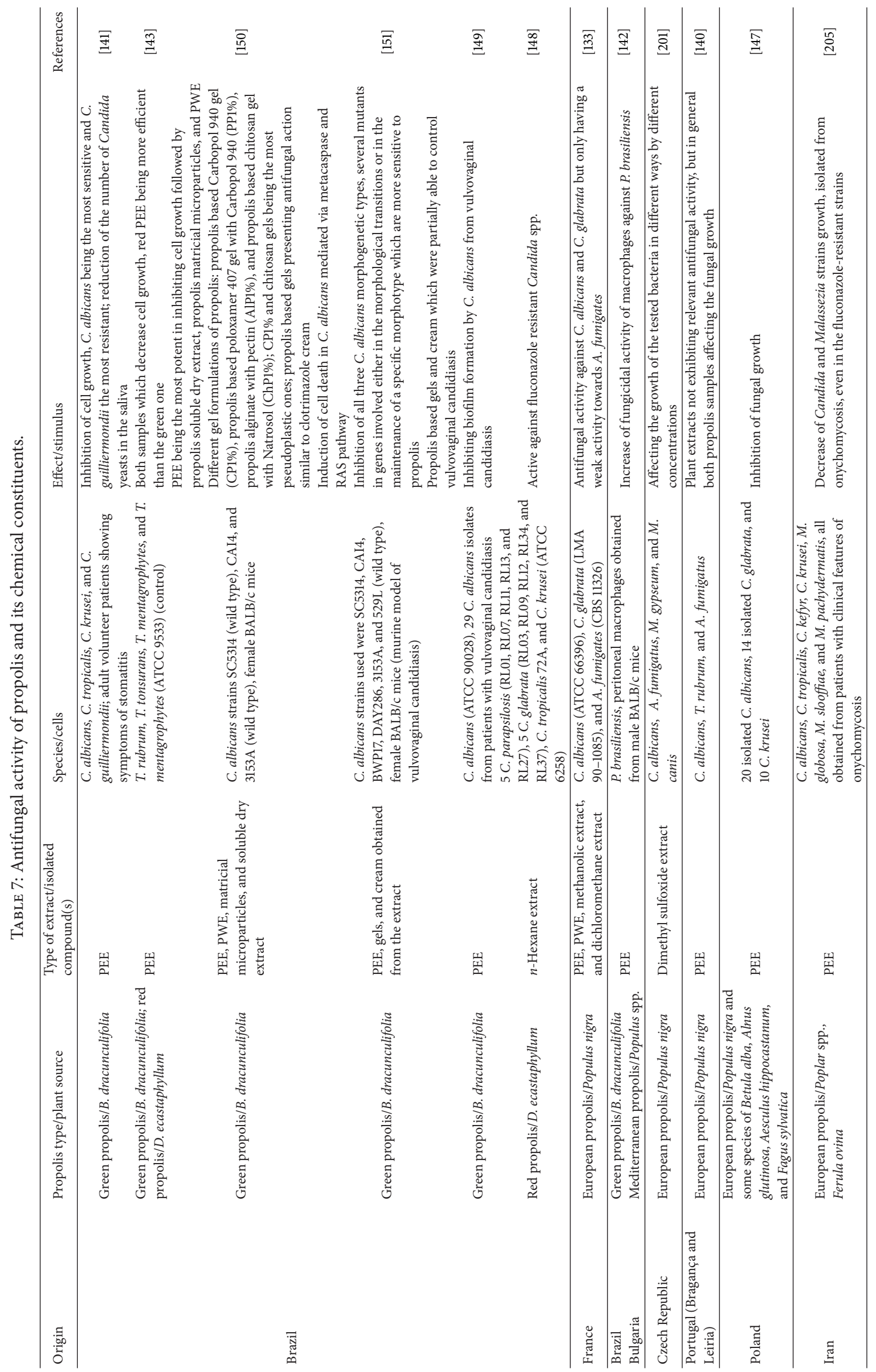




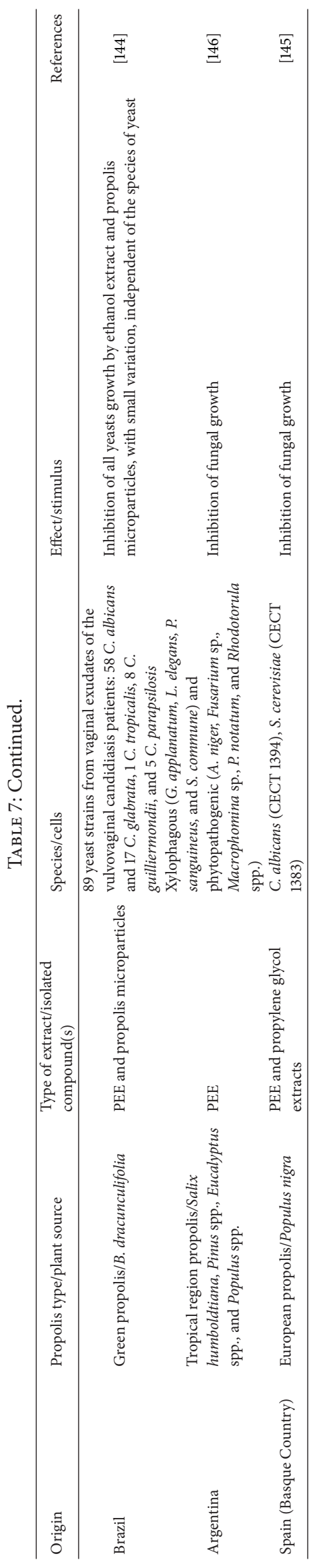


mechanism of CAPE. H. pylori, a major factor for gastrointestinal illnesses, contains the enzyme $H$. pylori peptide deformylase that catalyses the removal of formyl group from the N-terminus of nascent polypeptide chains. Since the action of this enzyme is essential for $H$. pylori survival, it is considered a promising therapeutic drug target. Results from absorption spectra and crystal structural characterization showed that CAPE is a competitive inhibitor of peptide deformylase, blocking the substrate entrance and preventing substrate from approaching the active site [131].

It has been suggested that the combination of propolis with other antibiotics would allow dose reduction of selected antibiotics, thus potentiating their effect. The antibacterial activity of Italian PEE in some clinically isolated Grampositive strains, as well as the synergetic effect with some antibiotics, was assessed by Scazzocchio et al. [56]. Italian PEE drastically increased the effect of ampicillin, gentamycin, and streptomycin and moderated the action of chloramphenicol, ceftriaxone, and vancomycin. No effect was observed when used simultaneously with erythromycin. Wojtyczka et al. [132] evaluated the in vitro antimicrobial activity of a Polish PEE against methicillin-sensitive $S$. aureus (MSSA) and methicillin-resistant S. aureus (MRSA) clinical isolates and also the combined effect of propolis with ten selected antistaphylococcal drugs. PEE displayed varying effectiveness against twelve $S$. aureus strains and potentiated the antimicrobial effect of eight antistaphylococcal against all tested strains. No synergism was observed in the case of ciprofloxacin and chloramphenicol. In another study, the effect of dichloromethane extract of French propolis against different human pathogenic bacterial strains was also tested. Although Gram-negative bacteria were not susceptible to the extract, a significant antibacterial activity against both methicillin-resistant and methicillin-susceptible $S$. aureus strains was observed [133]. The same was confirmed by Velikova et al. [28] using different PEE from Bulgaria, Greece, Turkey, and Algeria. All the samples showed a good antibacterial activity against $S$. aureus but a week or lacking effect against E. coli. Australian PEE from stingless bee Tetragonula carbonaria also inhibited the growth of $S$. aureus. Nevertheless, it was less active against $P$. aeruginosa [42]. The same was observed by Papachroni et al. [53] using PEE from Cameroon and Congo.Contrary to these studies, Katircioglu and Mercan [134] showed that Turkish PEE was effective against Gram-negative bacteria like E. coli. Orsi et al. [135] investigated the possible synergism between Brazilian and Bulgarian propolis and antibiotics acting on DNA (ciprofloxacin and norfloxacin) and on metabolism (cotrimoxazole) in Salmonella typhi. Both samples had antibacterial activity, but no synergistic effect was detected.

Recently, the suitability of nanohydroxyapatite- (nanoHA-) based surfaces containing two Brazilian PEE (green and red ones) to prevent $S$. aureus bacterial growth and biofilm was studied. The nanoHA impregnated with the two highest concentrations (12 and $25 \mu \mathrm{g} / \mathrm{mL}$ ) of red PEE showed a remarkable reduction of $99 \%$ in the number of viable bacteria, while nanoHA with green PEE at same concentrations showed a reduction of 45 and $61 \%$. Moreover, the nanoHA impregnated with the highest concentration of red PEE was able to inhibit $80 \%$ of the staphylococcal biofilm formation [136].

Diverse studies show that as the composition of propolis varies from region to region, the antibacterial activity also displays some variations [59]. Susceptibility of different Gram-positive bacteria to PEE varies with the place of propolis collection [137]. The antibacterial effect was shown to be higher for samples from a wet-tropical rain foresttype climate. Other studies revealed the influence of propolis geographical origin on its antibacterial properties $[57,58,138$, 139]. Propolis from the north and centre of Portugal has a great activity against $S$. aureus $[58,140]$.

4.5.2. Antifungal Activity. Antifungal activity is also influenced by the chemical variation of propolis [59]. Several studies have shown the effect of propolis from different geographic origin against different fungi, particularly of clinical interest [141-145]. Quiroga et al. [146] demonstrated the antifungal activity of propolis from the northwest of Argentina, focusing their study on the environment and the development of agrochemicals with reduced economic costs, possibly containing propolis extracts and its isolated compounds, such as pinocembrin and galangin, as active principles.

Recently, Falcão et al. [140] screened the antifungal activity of Portuguese propolis and its potential floral sources Populus $x$ Canadensis and Cistus ladanifer against Candida albicans, Trichophyton rubrum, and Aspergillus fumigatus. Plant extracts did not exhibit relevant antifungal activity, with exception of T. rubrum, but both propolis samples revealed similar antifungal activity, the highest being obtained against T. rubrum and the lowest against A. fumigatus. A sample of PEE from Poland showed a high fungicidal activity against C. albicans, C. glabrata, and C. krusei [147]. Recently, it was shown that different organic extracts of French propolis (PEE, PWE, methanolic extract, and dichloromethane extract) were effective against $C$. albicans and C. glabrata but only have a weak activity towards $A$. fumigates [133].

Brazilian PEE was proved to be active against several Candida strains (C. albicans, C. tropicalis, C. krusei, and C. guilliermondii), C. albicans being the most sensitive and C. guilliermondii the most resistant [141]. Brazilian green and red propolis display activity against different fungal species of Trichophyton, which cause dermatophytosis, red PEE being more efficient than the green one [143]. Also, it was shown that $n$-hexane extract of Brazilian red propolis did not induce resistance in Candida spp. In fact it was active against Candida spp. resistant to antifungal agents, like fluconazole [148]. Dota et al. [144] evaluated the in vitro antifungal activity of PEE and propolis microparticles (PMs) obtained from a sample from Argentina against clinical yeast isolates of importance in the vulvovaginal candidiasis. $C$. albicans and non-C. albicans were inhibited by PEE and PMs, with small variation. Additionally, it was shown that Brazilian green PEE has the ability to inhibit growth and biofilm formation by C. albicans from vulvovaginal candidiasis [149]. Another study showed fungicide action of propolis (PEE, PWE, propolis matricial microparticles (PMM), and propolis soluble dry extract after 6-8-hour treatment against all three 
C. albicans morphotypes (yeast, pseudohyphae, and hyphae), PEE being the most potent followed by PSDE, PM, and PWE [150]. Brazilian propolis induces C. albicans cell death mediated via metacaspase, since the metacaspase mutant in C. albicans showed reduced sensitivity to propolis, and by the Ras pathway. Using C. albicans deletion libraries, it was possible to screen several mutants in genes involved either in the morphological transitions or in the maintenance of a specific morphotype that are more sensitive to propolis. To conclude the study, the authors also showed that propolis based gels and cream were partially able to control vulvovaginal candidiasis in a mouse model [151]. These studies [144] strongly indicate that propolis has a great potential to control vulvovaginal candidiasis, representing a promising alternative therapeutic strategy.

4.6. Antitumour Activity. Recognition of the hallmarks of cancer affects the search and development of new methods and therapeutic agents with a sufficiently large therapeutic window to kill tumour cells while sparing normal cells. In the last years, the natural product propolis has attracted a growing interest by a large number of researchers since it contains a variety of phytochemical compounds that may act through multiple pathways to reduce the development and other malignant characteristics of cancer cells.

Recently, several in vitro studies have demonstrated a cytotoxic action of propolis from different geographic origin and of some of its isolated compounds on various tumour cells. In vivo studies also show a potential in the development of new antitumor agents, since propolis administration to mammals (e.g., rats) does not lead to detectable side effects [3]. Briefly, this natural product can block specific oncogene signalling pathways, which in turn lead to a decrease in cell proliferation and growth and can also act by decreasing the cancer stem cell population, increasing apoptosis, exerting antiangiogenic effects, and modulating the tumour microenvironment $[66,152,153]$. Table 8 summarizes the antitumour activity of propolis from different geographic origin and its chemical constituents.

Some researchers showed the effect of different types of propolis and its constituents on cancer cell growth, proliferation, and apoptosis. The hexane extract of propolis from Thailand, collected by the stingless bee Trigona laeviceps, which has a different behavior in propolis collection compared to the honey bees, exerts antiproliferative activity against five tested cancer cell lines (Chago, KATO-III, SW620, BT474, and Hep-G2) but not against the normal cell lines tested (HS27 fibroblast and $\mathrm{CH}$-liver) [5]. A sample of PEE from Poland inhibited human malignant melanoma (Me45) and colorectal cancer (HCT 116) cells growth, as well as reduced cell size [154]. Other studies reported the antitumor activity of Brazilian PEE [155-158] which regulate the protein expression of cyclin D1, B1 and cyclin dependent kinase (CDK) as well as p21 in human prostate cancer cells, significantly affecting proliferation [158].

Although propolis containing CAPE is different from those with artepillin $C$, it is possible to obtain a similar inhibitory effect from both types. The effect of CAPE on different cancer cell lines was analysed and many of its effects have been shown to be mediated through inhibition of NF- $\kappa \mathrm{B}[66,159]$. CAPE can inhibit the proliferation of the colorectal cell line SW480 by decreasing the $\beta$-catenin, cmyc, and cyclin D1 protein expression [160]. Chuu et al. [161] observed that CAPE suppressed the proliferation of LNCaP, DU-145, and PC-3 human prostate cancer cells in a dosedependent manner and also inhibited the tumour growth of LNCaP xenografts in nude mice. It was suggested that it acted through inhibition of p70S6K (an intermediary of the $\mathrm{PI} 3 \mathrm{~K} / \mathrm{AKT}$ pathway responsible for the protein synthesis) and some Akt signalling networks. Wu et al. [162] demonstrated that CAPE inhibits in vitro and in vivo MCF-7 and MDA-MB231 tumour growth without much effect on normal mammary cells by reducing the expression of growth and transcription factors, including NF- $\kappa$ B. Recently, it was demonstrated that CAPE effect on genes that are associated with tumour cell growth and survival is related in part to its role as a histone deacetylase inhibitor [163].

As previously said, propolis can also act by decreasing the cancer stem cell population. Using the putative CD44 $(+) / \mathrm{CD} 24$ (-/low) breast cancer stem cells able to generate mammospheres from single cells, Omene et al. [164] showed that CAPE caused a dose-dependent inhibition of cancer stem cells self-renewal, progenitor formation, and clonal growth.

Concerning cell death, some in vitro studies showed different sensitivities of tumour cells to propolis extracts. PWE from Iraq inhibits the proliferation of HL-60 cells and leads to downregulation of Bcl-2 and activation of Bax [13]. Alizadeh et al. [165] investigated the protective effects of Iranian PEE on N-methyl-N-nitro-N-nitrosoguanidine(MNNG-) initiated gastric cancer in rats. Results showed that tumour incidence, the number of lesions, structural abnormalities, and beta-catenin of the animals group treated with PEE significantly declined compared with the control. PEE also induced the expression of proapoptotic Bax and reduced antiapoptotic Bcl-2 expression. Propolis inhibits colony formation potential and promotes necrotic changes in HCT-116 cells and decreases mitotic cells and increases p53 and Ki-67 expression in HCT-116 tumor-bearing mice [13]. Szliszka's group have performed many studies to analyze the antitumour effect of different propolis and its constituents on prostate cancer cells (LNCaP and DU145) [166-168]. Brazilian green PEE sensitized these cells to TRAIL-induced death, enhanced the expression of TRAIL-R2, and decreased the activity of NF- $\kappa \mathrm{B}$ in LNCaP cells [167]. Cotreatment of TRAIL with artepillin $C$ induced the significant activation of caspase- 8 and caspase- 3 , as well as a significant disruption of the mitochondrial membrane potential [169]. Many studies have been conducted to understand the pathways involved in the apoptotic effect of CAPE. CAPE induces cell cycle arrest and apoptosis and reduces expression of NF- $\kappa \mathrm{B}$ in MDA-MB-231 and MCF-7 human breast cancer cells [162]. In PC3 prostate cancer cells, CAPE induced apoptosis in a dose-dependent manner that was associated with the loss of expression of the inhibitors of apoptosis: cIAP-1, cIAP-2, and XIAP [170]. Cavaliere et al. [171] showed that CAPE treatment 


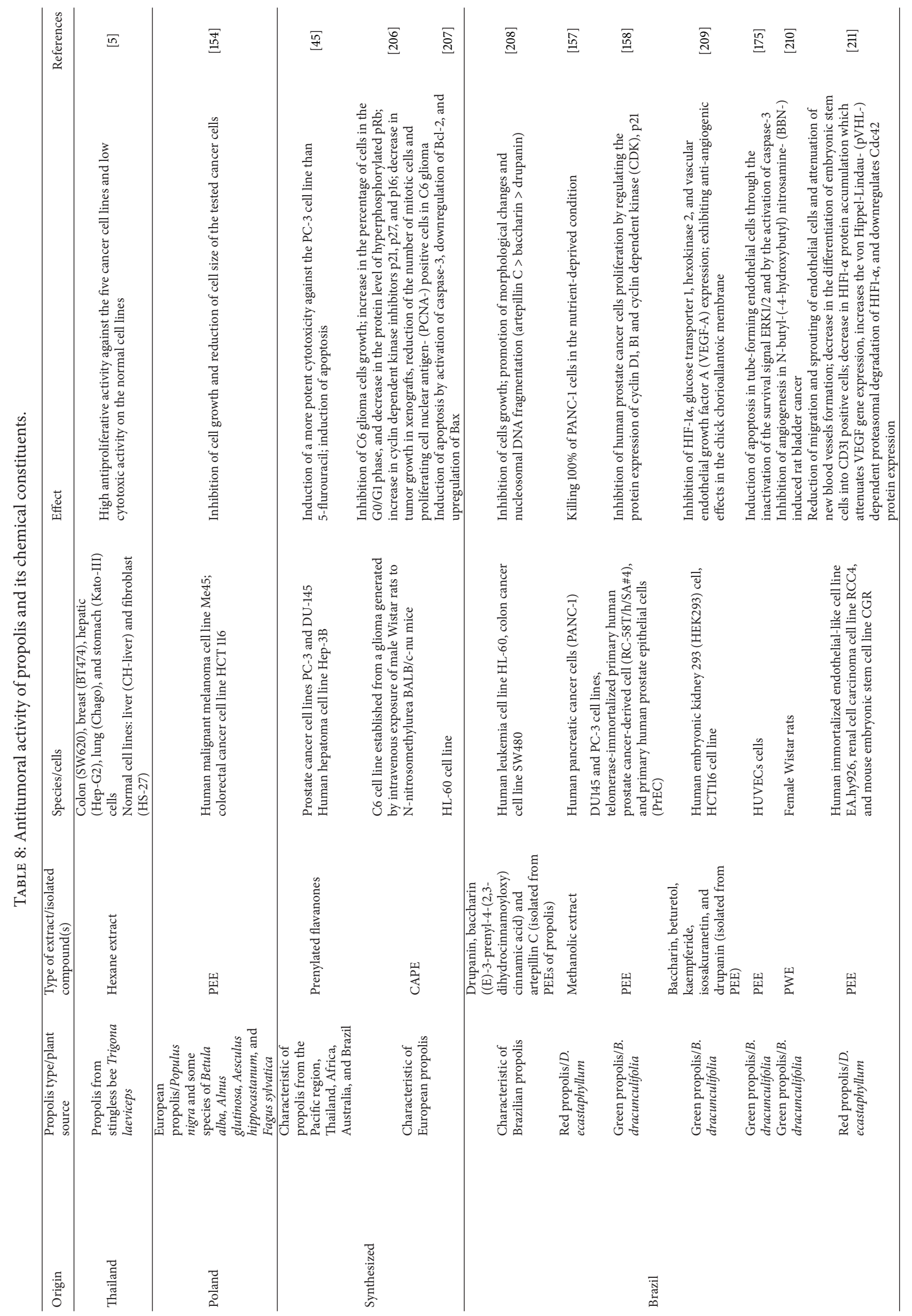




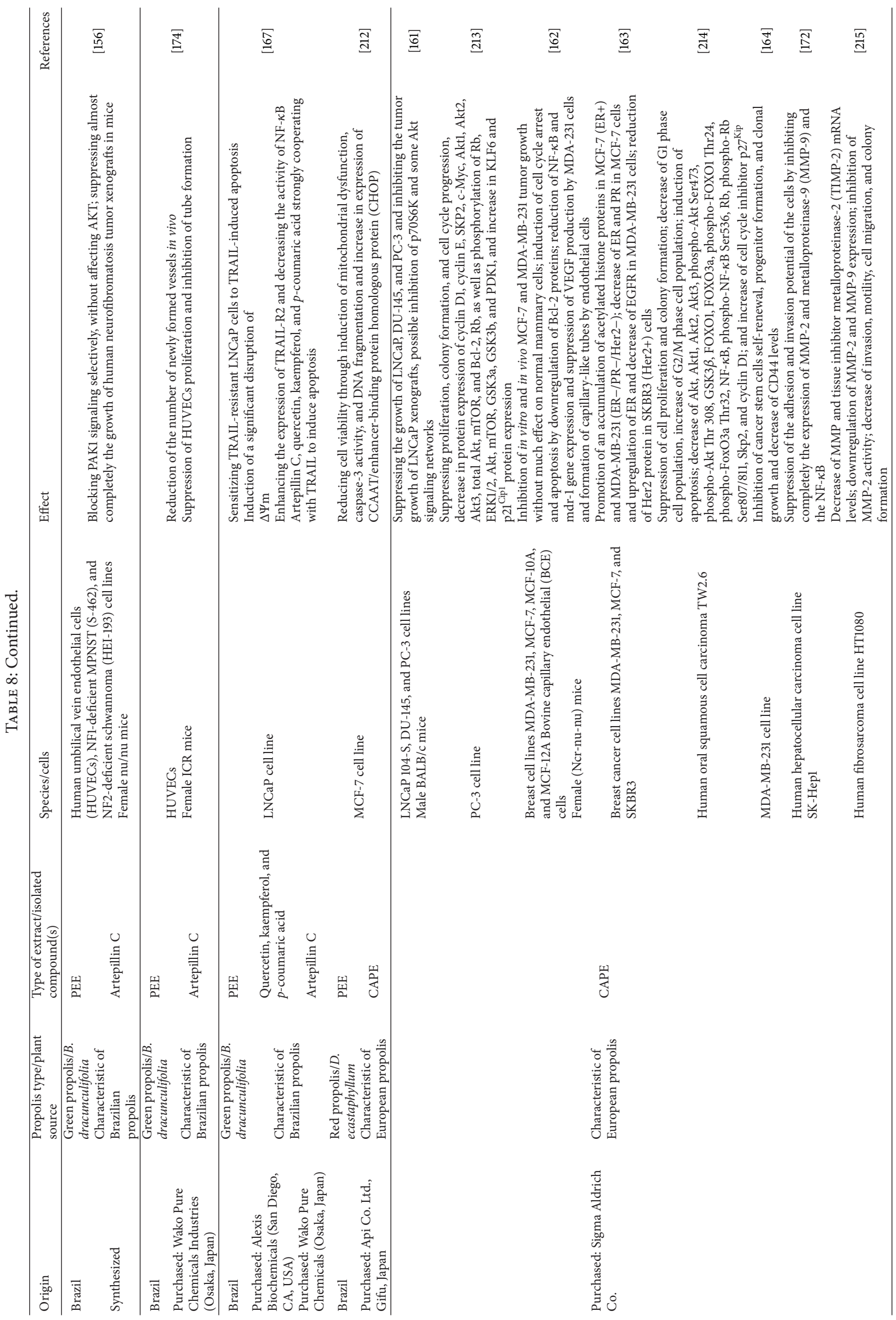




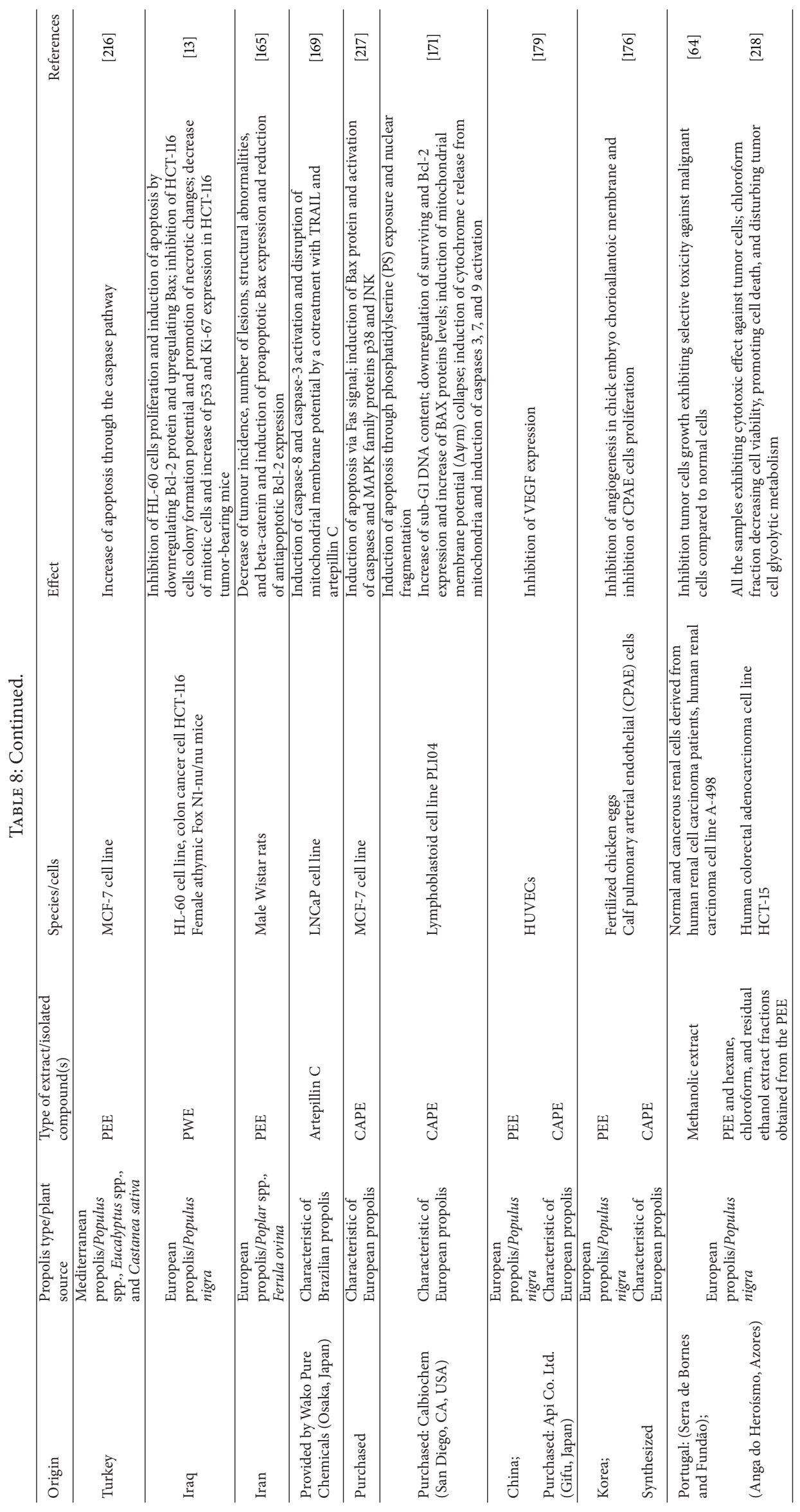


of lymphoblastoid cell line PL104 induced apoptosis through the mitochondrial intrinsic pathway.

It has been known that cancer microenvironment is very important for carcinogenesis and it consists of stromal, endothelial, immune, and cancer cells. Natural products, like propolis and their constituents, have been shown to interfere with this symbiosis. It was demonstrated by Lee et al. [172] that CAPE could effectively suppress the adhesion and invasion potential of human hepatocellular carcinoma cells (SK-Hep1) by inhibiting the expression of MMP-2 and MMP9 and NF- $\kappa$ B.

Angiogenesis has a crucial role in tumour growth due to the requirement of oxygen and nutrients to sustain rapid uncontrolled proliferation and metastization. Both tumour and stromal cells can secrete proangiogenic factors that stimulate the formation and maintenance of new vessels, such as vascular endothelial growth factor (VEGF) [173]. Brazilian PEE could significantly reduce the number of newly formed vessels and suppress the proliferation of human umbilical vein endothelial cells (HUVECs) [174], this antiangiogenic effect being mainly mediated via inducing apoptosis in tubeforming endothelial cells through the inactivation of the survival signal ERK1/2 [175]. Yun et al. [176] observed that CAPE inhibited angiogenesis using the in vivo assay chick embryo chorioallantoic membrane (CAM). CAPE also suppresses VEGF formation by MDA-MB-231 cells and formation of capillary-like tubes by endothelial cells $[162,177]$. Extracts of propolis containing artepillin C and CAPE significantly reduced the newly formed vessels and expression of MMPs and VEGF production from various cells [178] and, in accordance with this study, Izuta et al. [179] described that CAPE promotes inhibition of VEGF expression in HUVEC cells.

The first study on the antitumor activity of Portuguese propolis was only performed in 2010. Using normal and cancerous renal cells derived from human renal cell carcinoma (RCC) patients, in addition to A-498 cell line, Valente et al. [64] showed that methanolic extract of Portuguese propolis exhibited selective toxicity against malignant cells compared to normal cells and in vitro RCC growth was strongly inhibited. Recently, our group demonstrated the antitumour and antiangiogenic activity of the ethanol extract of Pereiro propolis (P10.EE), collected in the district of Guarda, Portugal. P10.EE affects cell viability of different tumour cells, MDA-MB-231 (breast) and DU145 (prostate) being two of the most sensitive ones, but was less cytotoxic against nontumour cells and fibroblasts. Also, it significantly decreased MDA-MB-231 and DU145 cell proliferation and migration along time, with cell cycle changes, and increased cell death. The significant increase observed in glucose consumption and lactate production could be explained in MDA-MB-231 by an increased expression of hypoxia inducible factor- $1 \alpha$, pyruvate dehydrogenase kinase, glucose transporter 1, lactate dehydrogenase, and carbonic anhydrase. Furthermore, P10.EE induced a decrease in HBMECs total biomass and proliferation and decreased vessel sprouting in the chicken chorioallantoic membrane [23].

\section{Conclusions}

From ancient to modern times, herbs and other plant products have been widely used as medicinal agents, first in folk medicine and other activities in many parts of the world and later developed and improved on a scientific basis into drugs that are used in the health system. Propolis is one of the few natural products that has maintained its popularity over a long period of time. As reviewed here, propolis contains a broad spectrum of compounds that may be useful in the treatment of different pathological conditions. In fact there is much literature that deals with the in vitro and in vivo biological properties of propolis. This wide range of bioactivities, the continuous discovery of new compounds, the long history of propolis use, and its safety profile make propolis a potential candidate for drug discovery that may be useful in several clinical scenarios. Nevertheless, it is necessary to make an effort to standardize propolis composition since it seems that propolis biological properties and chemical composition not only are variable but also are strictly linked. In our opinion, propolis extracts may be important economically and would allow a relatively inexpensive treatment in different diseases; however, to promote its use in modern medicine, it will be necessary to identify and isolate the bioactive compounds to be tested separately or in combination with other drugs already available.

Drug discovery does not consist only of the isolation of bioactive lead compounds from the natural sources. In fact, this process continues outside the academic laboratories through preclinical studies followed by clinical trials. Thus, despite the in vitro and in vivo assays, which provide new valuable information on propolis biological properties and mechanisms of action, it will be necessary to analyse the effectiveness of propolis clinically, to complement the basic research available, and to evaluate the potential of propolis in human health promotion.

\section{Abbreviations \\ CAPE: Caffeic acid phenethyl ester \\ PEE: Propolis ethanol extract \\ PWE: Propolis water extract \\ RNS: Reactive nitrogen species \\ ROS: Reactive oxygen species \\ VEGF: Vascular endothelial growth factor.}

\section{Conflict of Interests}

The authors declare that there is no conflict of interests regarding the publication of this paper.

\section{References}

[1] M. Gordaliza, "Natural products as leads to anticancer drugs," Clinical and Translational Oncology, vol. 9, no. 12, pp. 767-776, 2007.

[2] D. J. Newman and G. M. Cragg, "Natural products as sources of new drugs over the last 25 years," Journal of Natural Products, vol. 70, no. 3, pp. 461-477, 2007. 
[3] M. A. E. Watanabe, M. K. Amarante, B. J. Conti, and J. M. Sforcin, "Cytotoxic constituents of propolis inducing anticancer effects: a review," Journal of Pharmacy and Pharmacology, vol. 63, no. 11, pp. 1378-1386, 2011.

[4] K.-H. Lee, "Current developments in the discovery and design of new drug candidates from plant natural product leads," Journal of Natural Products, vol. 67, no. 2, pp. 273-283, 2004.

[5] S. Umthong, P. Phuwapraisirisan, S. Puthong, and C. Chanchao, "In vitro antiproliferative activity of partially purified Trigona laeviceps propolis from Thailand on human cancer cell lines," BMC Complementary and Alternative Medicine, vol. 11, article 37, 2011.

[6] J. M. Sforcin and V. Bankova, "Propolis: is there a potential for the development of new drugs?" Journal of Ethnopharmacology, vol. 133, no. 2, pp. 253-260, 2011.

[7] M. Marcucci, "Propolis: chemical composition, biological properties and therapeutic activity," Apidologie, vol. 26, no. 2, pp. 8399, 1995.

[8] Y. Barlak, O. Deǧer, M. Çolak, S. C. Karatayli, A. M. Bozdayi, and F. Yücesan, "Effect of Turkish propolis extracts on proteome of prostate cancer cell line," Proteome Science, vol. 9, article 74, 2011.

[9] V. Bankova, "Chemical diversity of propolis and the problem of standardization," Journal of Ethnopharmacology, vol. 100, no. 12, pp. 114-117, 2005.

[10] V. S. Bankova, S. L. de Castro, and M. C. Marcucci, "Propolis: recent advances in chemistry and plant origin," Apidologie, vol. 31, no. 1, pp. 3-15, 2000.

[11] S. M. Cardoso, M. Ribeiro, I. L. Ferreira, and A. Cristina Rego, "Northeast Portuguese propolis protects against staurosporine and hydrogen peroxide-induced neurotoxicity in primary cortical neurons," Food and Chemical Toxicology, vol. 49, no. 11, pp. 2862-2868, 2011.

[12] H. Fokt, A. Pereira, A. M. Ferreira, A. Cunha, and C. Aguiar, "How do bees prevent hive infections? The antimicrobial properties of propolis," in Current Research, Technology and Education Topics in Applied Microbiology and Microbial Biotechnology, A. Mendez-Vilas, Ed., vol. 1 of Microbiology Book SeriesNumber 2, pp. 481-493, 2010.

[13] G. M. Sulaiman, A. H. Ad'hiah, K. W. Al-Sammarrae et al., "Assessing the anti-tumour properties of Iraqi propolis in vitro and in vivo," Food and Chemical Toxicology, vol. 50, no. 5, pp. 1632-1641, 2012.

[14] N. Orsolic, S. Terzic, Z. Mihaljevic, L. Sver, and I. Basic, "Effects of local administration of propolis and its polyphenolic compounds on tumor formation and growth," Biological and Pharmaceutical Bulletin, vol. 28, no. 10, pp. 1928-1933, 2005.

[15] S. Castaldo and F. Capasso, "Propolis, an old remedy used in modern medicine," Fitoterapia, vol. 73, supplement 1, pp. S1-S6, 2002.

[16] G. A. Burdock, "Review of the biological properties and toxicity of bee propolis (propolis)," Food and Chemical Toxicology, vol. 36, no. 4, pp. 347-363, 1998.

[17] M. L. Khalil, "Biological activity of bee propolis in health and disease," Asian Pacific Journal of Cancer Prevention, vol. 7, no. 1, pp. 22-31, 2006.

[18] J. B. Daleprane, V. da Silva Freitas, A. Pacheco et al., "Antiatherogenic and anti-angiogenic activities of polyphenols from propolis," Journal of Nutritional Biochemistry, vol. 23, no. 6, pp. 557-566, 2012.
[19] A. H. Banskota, Y. Tezuka, and S. Kadota, "Recent progress in pharmacological research of propolis," Phytotherapy Research, vol. 15, no. 7, pp. 561-571, 2001.

[20] S. I. Falcão, M. Vilas-Boas, L. M. Estevinho, C. Barros, M. R. M. Domingues, and S. M. Cardoso, "Phenolic characterization of Northeast Portuguese propolis: usual and unusual compounds," Analytical and Bioanalytical Chemistry, vol. 396, no. 2, pp. 887897, 2010.

[21] S. I. Falcão, N. Vale, P. Gomes et al., "Phenolic profiling of Portuguese propolis by LC-MS spectrometry: uncommon propolis rich in flavonoid glycosides," Phytochemical Analysis, vol. 24, no. 4, pp. 309-318, 2013.

[22] L.-P. Sun, A.-L. Chen, H.-C. Hung et al., "Chrysin: a histone deacetylase 8 inhibitor with anticancer activity and a suitable candidate for the standardization of Chinese propolis," Journal of Agricultural and Food Chemistry, vol. 60, no. 47, pp. 1174811758, 2012.

[23] R. Silva-Carvalho, V. Miranda-Gonçalves, A. M. Ferreira et al., "Antitumoural and antiangiogenic activity of Portuguese propolis in in vitro and in vivo models," Journal of Functional Foods, vol. 11, pp. 160-171, 2014.

[24] M. P. Popova, K. Graikou, I. Chinou, and V. S. Bankova, "GCMS profiling of diterpene compounds in mediterranean propolis from Greece," Journal of Agricultural and Food Chemistry, vol. 58, no. 5, pp. 3167-3176, 2010.

[25] Ö. G. Çelemli, F. Hatjina, L. Charistos, A. Schiesser, and A. Özkirim, "More insight into the chemical composition of Greek propolis; differences and similarities with Turkish propolis," Zeitschrift für Naturforschung C, vol. 68, no. 11-12, pp. 429-438, 2013.

[26] V. Bankova, M. Popova, S. Bogdanov, and A.-G. Sabatini, "Chemical composition of European propolis: expected and unexpected results," Zeitschrift für Naturforschung Section C, vol. 57, no. 5-6, pp. 530-533, 2002.

[27] M. Popova, B. Trusheva, D. Antonova et al., "The specific chemical profile of Mediterranean propolis from Malta," Food Chemistry, vol. 126, no. 3, pp. 1431-1435, 2011.

[28] M. Velikova, V. Bankova, K. Sorkun, S. Houcine, I. Tsvetkova, and A. Kujumgiev, "Propolis from the Mediterranean region: chemical composition and antimicrobial activity," Zeitschrift für Naturforschung C, vol. 55, no. 9-10, pp. 790-793, 2000.

[29] S. Silici, M. Ünlü, and G. Vardar-Ünlü, "Antibacterial activity and phytochemical evidence for the plant origin of Turkish propolis from different regions," World Journal of Microbiology and Biotechnology, vol. 23, no. 12, pp. 1797-1803, 2007.

[30] N. Duran, M. Muz, G. Culha, G. Duran, and B. Ozer, "GC-MS analysis and antileishmanial activities of two Turkish propolis types," Parasitology Research, vol. 108, no. 1, pp. 95-105, 2011.

[31] A. L. Piccinelli, T. Mencherini, R. Celano et al., "Chemical composition and antioxidant activity of Algerian propolis," Journal of Agricultural and Food Chemistry, vol. 61, no. 21, pp. 5080-5088, 2013.

[32] Y. K. Park, S. M. Alencar, and C. L. Aguiar, "Botanical origin and chemical composition of Brazilian propolis," Journal of Agricultural and Food Chemistry, vol. 50, no. 9, pp. 2502-2506, 2002.

[33] C. O. da Silva Frozza, C. S. C. Garcia, G. Gambato et al., "Chemical characterization, antioxidant and cytotoxic activities of Brazilian red propolis," Food and Chemical Toxicology, vol. 52, pp. 137-142, 2013.

[34] A. Daugsch, C. S. Moraes, P. Fort, and Y. K. Park, "Brazilian red propolis-chemical composition and botanical origin," 
Evidence-Based Complementary and Alternative Medicine, vol. 5, no. 4, pp. 435-441, 2008.

[35] B. B. Silva, P. L. Rosalen, J. A. Cury et al., "Chemical composition and botanical origin of red propolis, a new type of Brazilian propolis," Evidence-Based Complementary and Alternative Medicine, vol. 5, no. 3, pp. 313-316, 2008.

[36] O. Cuesta-Rubio, B. A. Frontana-Uribe, T. Ramírez-Apan, and J. Cárdenas, "Polyisoprenylated benzophenones in Cuban propolis; biological activity of nemorosone," Zeitschrift für Naturforschung C, vol. 57, no. 3-4, pp. 372-378, 2002.

[37] B. Trusheva, M. Popova, H. Naydenski, I. Tsvetkova, J. G. Rodriguez, and V. Bankova, "New polyisoprenylated benzophenones from Venezuelan propolis," Fitoterapia, vol. 75, no. 7-8, pp. 683-689, 2004.

[38] F. A. Tomás-Barberán, C. García-Viguera, P. Vit-Olivier, F. Ferreres, and F. Tomás-Lorente, "Phytochemical evidence for the botanical origin of tropical propolis from Venezuela," Phytochemistry, vol. 34, no. 1, pp. 191-196, 1993.

[39] A. Abu-Mellal, N. Koolaji, R. K. Duke, V. H. Tran, and C. C. Duke, "Prenylated cinnamate and stilbenes from Kangaroo Island propolis and their antioxidant activity," Phytochemistry, vol. 77, pp. 251-259, 2012.

[40] V.H. Tran, R. K. Duke, A. Abu-Mellal, and C. C. Duke, "Propolis with high flavonoid content collected by honey bees from Acacia paradoxa," Phytochemistry, vol. 81, pp. 126-132, 2012.

[41] E. L. Ghisalberti, P. R. Jefferies, R. Lanteri, and J. Matisons, "Constituents of propolis," Experientia, vol. 34, no. 2, pp. 157$158,1978$.

[42] C. F. Massaro, M. Katouli, T. Grkovic et al., "Anti-staphylococcal activity of $\mathrm{C}$-methyl flavanones from propolis of Australian stingless bees (Tetragonula carbonaria) and fruit resins of Corymbia torelliana (Myrtaceae)," Fitoterapia, vol. 95, pp. 247257, 2014.

[43] S. Kumazawa, H. Goto, T. Hamasaka, S. Fukumoto, T. Fujimoto, and T. Nakayama, "A new prenylated flavonoid from propolis collected in Okinawa, Japan," Bioscience, Biotechnology and Biochemistry, vol. 68, no. 1, pp. 260-262, 2004.

[44] S. Inui, T. Hosoya, and S. Kumazawa, "Hawaiian propolis: comparative analysis and botanical origin," Natural Product Communications, vol. 9, no. 2, pp. 165-166, 2014.

[45] C.-N. Chen, C.-J. Hsiao, S.-S. Lee et al., "Chemical modification and anticancer effect of prenylated flavanones from Taiwanese propolis," Natural Product Research, vol. 26, no. 2, pp. 116-124, 2012.

[46] B. Trusheva, M. Popova, E. B. Koendhori, I. Tsvetkova, C. Naydenski, and V. Bankova, "Indonesian propolis: chemical composition, biological activity and botanical origin," Natural Product Research, vol. 25, no. 6, pp. 606-613, 2011.

[47] F. Li, S. Awale, H. Zhang, Y. Tezuka, H. Esumi, and S. Kadota, "Chemical constituents of propolis from Myanmar and their preferential cytotoxicity against a human pancreatic cancer cell line," Journal of Natural Products, vol. 72, no. 7, pp. 1283-1287, 2009.

[48] S. Athikomkulchai, S. Awale, N. Ruangrungsi, S. Ruchirawat, and S. Kadota, "Chemical constituents of Thai propolis," Fitoterapia, vol. 88, pp. 96-100, 2013.

[49] V. S. Bankova, R. S. Christov, and A. D. Tejera, "Lignans and other constituents of propolis from the canary islands," Phytochemistry, vol. 49, no. 5, pp. 1411-1415, 1998.

[50] A. Petrova, M. Popova, C. Kuzmanova et al., "New biologically active compounds from Kenyan propolis," Fitoterapia, vol. 81, no. 6, pp. 509-514, 2010.
[51] M. Popova, R. Dimitrova, H. T. Al-Lawati, I. Tsvetkova, H. Najdenski, and V. Bankova, "Omani propolis: chemical profiling, antibacterial activity and new propolis plant sources," Chemistry Central Journal, vol. 7, no. 1, article 158, 2013.

[52] A. I. Rushdi, N. Adgaba, N. I. Bayaqoob et al., "Characteristics and chemical compositions of propolis from Ethiopia," SpringerPlus, vol. 3, no. 1, p. 253, 2014.

[53] D. Papachroni, K. Graikou, I. Kosalec, H. Damianakos, V. Ingram, and I. Chinou, "Phytochemical analysis and biological evaluation of selected African propolis samples from Cameroon and Congo," Natural Product Communications, vol. 10, no. 1, pp. 67-70, 2015.

[54] T. Zhang, R. Omar, W. Siheri et al., "Chromatographic analysis with different detectors in the chemical characterisation and dereplication of African propolis," Talanta, vol. 120, pp. 181-190, 2014.

[55] A. Kurek-Górecka, A. Rzepecka-Stojko, M. Górecki, J. Stojko, M. Sosada, and G. Swierczek-Zieba, "Structure and antioxidant activity of polyphenols derived from propolis," Molecules, vol. 19, no. 1, pp. 78-101, 2014.

[56] F. Scazzocchio, F. D. D’Auria, D. Alessandrini, and F. Pantanella, "Multifactorial aspects of antimicrobial activity of propolis," Microbiological Research, vol. 161, no. 4, pp. 327-333, 2006.

[57] R. M. Ordóñez, I. C. Zampini, M. I. N. Moreno, and M. I. Isla, "Potential application of Northern Argentine propolis to control some phytopathogenic bacteria," Microbiological Research, vol. 166, no. 7, pp. 578-584, 2011.

[58] J. C. Silva, S. Rodrigues, X. Feás, and L. M. Estevinho, "Antimicrobial activity, phenolic profile and role in the inflammation of propolis," Food and Chemical Toxicology, vol. 50, no. 5, pp. 1790-1795, 2012.

[59] A. Kujumgiev, I. Tsvetkova, Y. Serkedjieva, V. Bankova, R. Christov, and S. Popov, "Antibacterial, antifungal and antiviral activity of propolis of different geographic origin," Journal of Ethnopharmacology, vol. 64, no. 3, pp. 235-240, 1999.

[60] M. Amoros, C. M. O. Simões, L. Girre, F. Sauvager, and M. Cormier, "Synergistic effect of flavones and flavonols against herpes simplex virus type 1 in cell culture. Comparison with the antiviral activity of propolis," Journal of Natural Products, vol. 55, no. 12, pp. 1732-1740, 1992.

[61] F. Hu, H. R. Hepburn, Y. Li, M. Chen, S. E. Radloff, and S. Daya, "Effects of ethanol and water extracts of propolis (bee glue) on acute inflammatory animal models," Journal of Ethnopharmacology, vol. 100, no. 3, pp. 276-283, 2005.

[62] L. Moreira, L. G. Dias, J. A. Pereira, and L. Estevinho, "Antioxidant properties, total phenols and pollen analysis of propolis samples from Portugal," Food and Chemical Toxicology, vol. 46, no. 11, pp. 3482-3485, 2008.

[63] M. G. Miguel, S. Nunes, S. A. Dandlen, A. M. Cavaco, and M. D. Antunes, "Phenols and antioxidant activity of hydro-alcoholic extracts of propolis from Algarve, South of Portugal," Food and Chemical Toxicology, vol. 48, no. 12, pp. 3418-3423, 2010.

[64] M. J. Valente, A. F. Baltazar, R. Henrique, L. Estevinho, and M. Carvalho, "Biological activities of Portuguese propolis: protection against free radical-induced erythrocyte damage and inhibition of human renal cancer cell growth in vitro," Food and Chemical Toxicology, vol. 49, no. 1, pp. 86-92, 2011.

[65] N. Oršolić and I. Bašić, "Immunomodulation by water-soluble derivative of propolis: a factor of antitumor reactivity," Journal of Ethnopharmacology, vol. 84, no. 2-3, pp. 265-273, 2003.

[66] G. C.-F. Chan, K.-W. Cheung, and D. M.-Y. Sze, "The immunomodulatory and anticancer properties of propolis," 
Clinical Reviews in Allergy and Immunology, vol. 44, no. 3, pp. 262-273, 2013.

[67] R. C. Calhelha, S. Falcão, M. J. Queiroz, M. Vilas-Boas, and I. C. Ferreira, "Cytotoxicity of portuguese propolis: the proximity of the in vitro doses for tumor and normal cell lines," BioMed Research International, vol. 2014, 7 pages, 2014.

[68] V. Sosa, T. Moliné, R. Somoza, R. Paciucci, H. Kondoh, and M. E. LLeonart, "Oxidative stress and cancer: an overview," Ageing Research Reviews, vol. 12, no. 1, pp. 376-390, 2013.

[69] T. B. Salmon, B. A. Evert, B. Song, and P. W. Doetsch, "Biological consequences of oxidative stress-induced DNA damage in Saccharomyces cerevisiae," Nucleic Acids Research, vol. 32, no. 12, pp. 3712-3723, 2004.

[70] M. Viuda-Martos, Y. Ruiz-Navajas, J. Fernández-López, and J. A. Pérez-Álvarez, "Functional properties of honey, propolis, and royal jelly," Journal of Food Science, vol. 73, no. 9, pp. R117R124, 2008.

[71] Z. Wu, Y. Zhao, and B. Zhao, "Superoxide anion, uncoupling proteins and Alzheimer's disease," Journal of Clinical Biochemistry and Nutrition, vol. 46, no. 3, pp. 187-194, 2010.

[72] F. J. Pashkow, "Oxidative stress and inflammation in heart disease: do antioxidants have a role in treatment and/or prevention?" International Journal of Inflammation, vol. 2011, Article ID 514623, 9 pages, 2011.

[73] R. Schnabel and S. Blankenberg, "Oxidative stress in cardiovascular disease: successful translation from bench to bedside?" Circulation, vol. 116, no. 12, pp. 1338-1340, 2007.

[74] W. Ladiges, J. Wanagat, B. Preston, L. Loeb, and P. Rabinovitch, "A Mitochondrial view of aging, reactive oxygen species and metastatic cancer," Aging Cell, vol. 9, no. 4, pp. 462-465, 2010.

[75] M. A. Nader, D. S. El-Agamy, and G. M. Suddek, "Protective effects of propolis and thymoquinone on development of atherosclerosis in cholesterol-fed rabbits," Archives of Pharmacal Research, vol. 33, no. 4, pp. 637-643, 2010.

[76] A. Scalbert, I. T. Johnson, and M. Saltmarsh, "Polyphenols: antioxidants and beyond," The American Journal of Clinical Nutrition, vol. 81, no. 1, supplement, pp. 215S-217S, 2005.

[77] N. Almaraz-Abarca, M. da Graça Campos, J. A. Ávila-Reyes, N. Naranjo-Jiménez, J. Herrera Corral, and L. S. González-Valdez, "Antioxidant activity of polyphenolic extract of monofloral honeybee-collected pollen from mesquite (Prosopis juliflora, Leguminosae)," Journal of Food Composition and Analysis, vol. 20, no. 2, pp. 119-124, 2007.

[78] S. Fabris, M. Bertelle, O. Astafyeva et al., "Antioxidant properties and chemical composition relationship of europeans and Brazilians propolis," Pharmacology \& Pharmacy, vol. 4, no. 1, pp. 46-51, 2013.

[79] C. M. Mihai, L. A. Mărghitaş, D. S. Daniel, S. Dezmirean, and L. Bărnuţiu, "Correlation between polyphenolic profile and antioxidant activity of propolis from Transylvania," Animal Science and Biotechnologies, vol. 44, no. 2, pp. 100-103, 2011.

[80] G. G. Duthie, P. T. Gardner, and J. A. M. Kyle, "Plant polyphenols: are they the new magic bullet?" Proceedings of the Nutrition Society, vol. 62, no. 3, pp. 599-603, 2003.

[81] H. Yang, Y. Dong, H. Du, H. Shi, Y. Peng, and X. Li, "Antioxidant compounds from propolis collected in Anhui, China," Molecules, vol. 16, no. 4, pp. 3444-3455, 2011.

[82] V. Silva, G. Genta, M. N. Möller et al., "Antioxidant activity of Uruguayan propolis. In vitro and cellular assays," Journal of Agricultural and Food Chemistry, vol. 59, no. 12, pp. 6430-6437, 2011.
[83] P. Bolfa, R. Vidrighinescu, A. Petruta et al., "Photoprotective effects of Romanian propolis on skin of mice exposed to UVB irradiation," Food and Chemical Toxicology, vol. 62, pp. 329-342, 2013.

[84] Z. Talas, I. Ozdemir, O. Ciftci, M. Gulhan, and A. Savci, "Antioxidant effect of ethanolic extract of propolis in liver of L-name treated rats," Advances in Clinical and Experimental Medicine, vol. 24, no. 2, pp. 227-232, 2015.

[85] A. Russo, R. Longo, and A. Vanella, "Antioxidant activity of propolis: role of caffeic acid phenethyl ester and galangin," Fitoterapia, vol. 73, supplement 1, pp. S21-S29, 2002.

[86] M. Hoşnuter, A. Gürel, O. Babucçu, F. Armutcu, E. Kargi, and A. Işikdemir, "The effect of CAPE on lipid peroxidation and nitric oxide levels in the plasma of rats following thermal injury," Burns, vol. 30, no. 2, pp. 121-125, 2004.

[87] Y.-J. Chen, A.-C. Huang, H.-H. Chang et al., "Caffeic acid phenethyl ester, an antioxidant from propolis, protects peripheral blood mononuclear cells of competitive cyclists against hyperthermal stress," Journal of Food Science, vol. 74, no. 6, pp. H162-H167, 2009.

[88] S. Reuter, S. C. Gupta, M. M. Chaturvedi, and B. B. Aggarwal, "Oxidative stress, inflammation, and cancer: how are they linked?” Free Radical Biology and Medicine, vol. 49, no. 11, pp. 1603-1616, 2010.

[89] G. Costa, V. Francisco, M. C. Lopes, M. T. Cruz, and M. T. Batista, "Intracellular signaling pathways modulated by phenolic compounds: application for new anti-inflammatory drugs discovery," Current Medicinal Chemistry, vol. 19, no. 18, pp. 2876-2900, 2012.

[90] O. K. Mirzoeva and P. C. Calder, "The effect of propolis and its components on eicosanoid production during the inflammatory response," Prostaglandins Leukotrienes and Essential Fatty Acids, vol. 55, no. 6, pp. 441-449, 1996.

[91] A. Rossi, A. Ligresti, R. Longo, A. Russo, F. Borrelli, and L. Sautebin, "The inhibitory effect of propolis and caffeic acid phenethyl ester on cyclooxygenase activity in J774 macrophages," Phytomedicine, vol. 9, no. 6, pp. 530-535, 2002.

[92] S. Chirumbolo, "The role of quercetin, flavonols and flavones in modulating inflammatory cell function," Inflammation and Allergy-Drug Targets, vol. 9, no. 4, pp. 263-285, 2010.

[93] E.-H. Park and J.-H. Kahng, "Suppressive effects of propolis in rat adjuvant arthritis," Archives of Pharmacal Research, vol. 22, no. 6, pp. 554-558, 1999.

[94] N. Márquez, R. Sancho, A. Macho, M. A. Calzado, B. L. Fiebich, and E. Muñoz, "Caffeic acid phenethyl ester inhibits T-cell activation by targeting both nuclear factor of activated T-cells and NF- $\kappa$ B transcription factors," Journal of Pharmacology and Experimental Therapeutics, vol. 308, no. 3, pp. 993-1001, 2004.

[95] Y. Naito, M. Yasumuro, K. Kondou, and N. Ohara, "Antiinflammatory effect of topically applied propolis extract in carrageenan-induced rat hind paw edema," Phytotherapy Research, vol. 21, no. 5, pp. 452-456, 2007.

[96] M. Funakoshi-Tago, K. Okamoto, R. Izumi et al., "Antiinflammatory activity of flavonoids in Nepalese propolis is attributed to inhibition of the IL-33 signaling pathway," International Immunopharmacology, vol. 25, no. 1, pp. 189-198, 2015.

[97] R. M. N. Bezerra, L. F. Veiga, A. C. Caetano et al., "Caffeic acid phenethyl ester reduces the activation of the nuclear factor kappab pathway by high-fat diet-induced obesity in mice," Metabolism: Clinical and Experimental, vol. 61, no. 11, pp. 16061614, 2012. 
[98] S. Juman, N. Yasui, K. Ikeda et al., "Caffeic acid phenethyl ester suppresses the production of pro-inflammatory cytokines in hypertrophic adipocytes through lipopolysaccharidestimulated macrophages," Biological and Pharmaceutical Bulletin, vol. 35, no. 11, pp. 1941-1946, 2012.

[99] J. L. Machado, A. K. Assuncao, M. C. da Silva et al., "Brazilian green propolis: anti-inflammatory property by an immunomodulatory activity," Evidence-Based Complementary and Alternative Medicine, vol. 2012, Article ID 157652, 10 pages, 2012.

[100] F. Teles, T. M. da Silva, F. P. da Cruz Júnior et al., "Brazilian red propolis attenuates hypertension and renal damage in 5/6 renal ablation model," PLoS ONE, vol. 10, no. 1, Article ID e0116535, 2015.

[101] M. C. Búfalo, I. Ferreira, G. Costa et al., "Propolis and its constituent caffeic acid suppress LPS-stimulated proinflammatory response by blocking NF- $\kappa \mathrm{B}$ and MAPK activation in macrophages," Journal of Ethnopharmacology, vol. 149, no. 1, pp. 84-92, 2013.

[102] G. Valenzuela-Barra, C. Castro, C. Figueroa et al., "Antiinflammatory activity and phenolic profile of propolis from two locations in Región Metropolitana de Santiago, Chile," Journal of Ethnopharmacology, vol. 168, pp. 37-44, 2015.

[103] L. H. Boudreau, J. Maillet, L. M. LeBlanc et al., "Caffeic acid phenethyl ester and its amide analogue are potent inhibitors of leukotriene biosynthesis in human polymorphonuclear leukocytes," PLoS ONE, vol. 7, no. 2, Article ID e31833, 2012.

[104] N. Oršolić, J. Skurić, D. Crossed D Signikić, and G. Stanić, "Inhibitory effect of a propolis on Di-n-Propyl Disulfide or n-Hexyl salycilate-induced skin irritation, oxidative stress and inflammatory responses in mice," Fitoterapia, vol. 93, pp. 18-30, 2014.

[105] C. L. Orsatti, F. Missima, A. C. Pagliarone et al., "Propolis immunomodulatory action in vivo on toll-like receptors 2 and 4 expression and on pro-inflammatory cytokines production in mice," Phytotherapy Research, vol. 24, no. 8, pp. 1141-1146, 2010.

[106] N. Ivanovska, H. Neychev, Z. Stefanova, V. Bankova, and S. Popov, "Influence of cinnamic acid on lymphocyte proliferation, cytokine release and Klebsiella infection in mice," Apidologie, vol. 26, no. 2, pp. 73-81, 1995.

[107] R. O. Orsi, S. R. Funari, A. M. V. C. Soares, and et al, "Immunomodulatory action of propolis on macrophage activation," Journal of Venomous Animals and Toxins, vol. 6, no. 2, pp. 205-219, 2000.

[108] A. Sá-Nunes, L. H. Faccioli, and J. M. Sforcin, "Propolis: Lymphocyte proliferation and IFN- $\gamma$ production," Journal of Ethnopharmacology, vol. 87, no. 1, pp. 93-97, 2003.

[109] F. Missima and J. M. Sforcin, "Green Brazilian propolis action on macrophages and lymphoid organs of chronically stressed mice," Evidence-Based Complementary and Alternative Medicine, vol. 5, no. 1, pp. 71-75, 2008.

[110] Syamsudin, R. M. Dewi, and Kusmardi, "Immunomodulatory and in vivo antiplasmodial activities of propolis extracts," American Journal of Pharmacology and Toxicology, vol. 4, no. 3, pp. 75-79, 2009.

[111] C. L. Orsatti and J. M. Sforcin, "Propolis immunomodulatory activity on TLR-2 and TLR- 4 expression by chronically stressed mice," Natural Product Research, vol. 26, no. 5, pp. 446-453, 2012.
[112] L.-C. Wang, Y.-L. Lin, Y.-C. Liang et al., "The effect of caffeic acid phenethyl ester on the functions of human monocytederived dendritic cells," BMC Immunology, vol. 10, article 39, 2009.

[113] M. C. Búfalo, A. P. Bordon-Graciani, B. J. Conti, M. de Assis Golim, and J. M. Sforcin, "The immunomodulatory effect of propolis on receptors expression, cytokine production and fungicidal activity of human monocytes," Journal of Pharmacy and Pharmacology, vol. 66, no. 10, pp. 1497-1504, 2014.

[114] M. C. Búfalo and J. M. Sforcin, "The modulatory effects of caffeic acid on human monocytes and its involvement in propolis action," Journal of Pharmacy and Pharmacology, vol. 67, no. 5, pp. 740-745, 2015.

[115] F. Missima, A. C. Pagliarone, C. L. Orsatti, and J. M. Sforcin, "The effect of propolis on pro-inflammatory cytokines produced by melanoma-bearing mice submitted to chronic stress," Journal of ApiProduct \& ApiMedical Science, vol. 1, no. 1, pp. 1115, 2009.

[116] T. F. Bachiega, C. L. Orsatti, A. C. Pagliarone, and J. M. Sforcin, "The effects of propolis and its isolated compounds on cytokine production by murine macrophages," Phytotherapy Research, vol. 26, no. 9, pp. 1308-1313, 2012.

[117] S. S. da Silva, S. Thome Gda, A. H. Cataneo et al., "Brazilian propolis antileishmanial and immunomodulatory effects," Evidence-Based Complementary and Alternative Medicine, vol. 2013, Article ID 673058, 7 pages, 2013.

[118] Y. Okamoto, T. Hara, T. Ebato, T. Fukui, and T. Masuzawa, "Brazilian propolis ameliorates trinitrobenzene sulfonic acidinduced colitis in mice by inhibiting Th1 differentiation," International Immunopharmacology, vol. 16, no. 2, pp. 178-183, 2013.

[119] G. Gekker, S. Hu, M. Spivak, J. R. Lokensgard, and P. K. Peterson, "Anti-HIV-1 activity of propolis in CD $4^{+}$lymphocyte and microglial cell cultures," Journal of Ethnopharmacology, vol. 102, no. 2, pp. 158-163, 2005.

[120] M. Amoros, F. Sauvager, L. Girre, and M. Cormier, "In vitro antiviral activity of propolis," Apidologie, vol. 23, no. 3, pp. 231240, 1992.

[121] J. Serkedjieva, N. Manolova, and V. Bankova, "Anti-influenza virus effect of some propolis constituents and their analogues (esters of substituted cinnamic acids)," Journal of Natural Products, vol. 55, no. 3, pp. 294-297, 1992.

[122] T. Shimizu, A. Hino, A. Tsutsumi, Y. K. Park, W. Watanabe, and M. Kurokawa, "Anti-influenza virus activity of propolis in vitro and its efficacy against influenza infection in mice," Antiviral Chemistry and Chemotherapy, vol. 19, no. 1, pp. 7-13, 2008.

[123] P. Schnitzler, A. Neuner, S. Nolkemper et al., "Antiviral activity and mode of action of propolis extracts and selected compounds," Phytotherapy Research, vol. 24, supplement 1, pp. S20S28, 2010.

[124] G. Sartori, A. P. Pesarico, S. Pinton et al., "Protective effect of brown Brazilian propolis against acute vaginal lesions caused by herpes simplex virus type 2 in mice: involvement of antioxidant and anti-inflammatory mechanisms," Cell Biochemistry and Function, vol. 30, no. 1, pp. 1-10, 2012.

[125] G. R. Coelho, R. Z. Mendonça, K. D. Vilar et al., "Antiviral action of hydromethanolic extract of geopropolis from Scaptotrigona postica against antiherpes simplex virus (HSV-1)," EvidenceBased Complementary and Alternative Medicine, vol. 2015, Article ID 296086, 10 pages, 2015.

[126] S. Tait, A. L. Salvati, N. Desideri, and L. Fiore, "Antiviral activity of substituted homoisoflavonoids on enteroviruses," Antiviral Research, vol. 72, no. 3, pp. 252-255, 2006. 
[127] J. Shvarzbeyn and M. Huleihel, "Effect of propolis and caffeic acid phenethyl ester (CAPE) on NF $\kappa$ B activation by HTLV-1 Tax," Antiviral Research, vol. 90, no. 3, pp. 108-115, 2011.

[128] X. Ma, Z. Guo, Z. Shen, Y. Liu, J. Wang, and Y. Fan, "The anti-porcine parvovirus activity of nanometer propolis flavone and propolis flavone in vitro and in vivo," Evidence-Based Complementary and Alternative Medicine, vol. 2015, Article ID 472876, 10 pages, 2015.

[129] J. Ito, F.-R. Chang, H.-K. Wang et al., "Anti-AIDS agents. 48. Anti-HIV activity of moronic acid derivatives and the new melliferone-related triterpenoid isolated from Brazilian propolis," Journal of Natural Products, vol. 64, no. 10, pp. 12781281, 2001.

[130] O. K. Mirzoeva, R. N. Grishanin, and P. C. Calder, "Antimicrobial action of propolis and some of its components: the effects on growth, membrane potential and motility of bacteria," Microbiological Research, vol. 152, no. 3, pp. 239-246, 1997.

[131] K. Cui, W. Lu, L. Zhu, X. Shen, and J. Huang, "Caffeic acid phenethyl ester (CAPE), an active component of propolis, inhibits Helicobacter pylori peptide deformylase activity," Biochemical and Biophysical Research Communications, vol. 435, no. 2, pp. 289-294, 2013.

[132] R. D. Wojtyczka, A. Dziedzic, D. Idzik et al., "Susceptibility of Staphylococcus aureus clinical isolates to propolis extract alone or in combination with antimicrobial drugs," Molecules, vol. 18, no. 8, pp. 9623-9640, 2013.

[133] S. Boisard, A. Le Ray, A. Landreau et al., "Antifungal and antibacterial metabolites from a French poplar type propolis," Evidence-Based Complementary and Alternative Medicine, vol. 2015, Article ID 319240, 10 pages, 2015.

[134] H. Katircioğlu and N. Mercan, "Antimicrobial activity and chemical compositions of Turkish propolis from different regions," African Journal of Biotechnology, vol. 5, no. 11, pp. 11511153, 2006.

[135] R. O. Orsi, A. Fernandes Jr., V. Bankova, and J. M. Sforcin, "Antibacterial effects of Brazilian and Bulgarian propolis and synergistic effects with antibiotics acting on the bacterial DNA and folic acid," Natural Product Research, vol. 26, no. 4, pp. 344349, 2012.

[136] L. Grenho, J. Barros, C. Ferreira et al., "In vitro antimicrobial activity and biocompatibility of propolis containing nanohydroxyapatite," Biomedical Materials, vol. 10, no. 2, Article ID 025004, 2015.

[137] V. Seidel, E. Peyfoon, D. G. Watson, and J. Fearnley, "Comparative study of the antibacterial activity of propolis from different geographical and climatic zones," Phytotherapy Research, vol. 22, no. 9, pp. 1256-1263, 2008.

[138] L. Monzote, O. Cuesta-Rubio, M. C. Fernandez et al., "In vitro antimicrobial assessment of Cuban propolis extracts," Memorias do Instituto Oswaldo Cruz, vol. 107, no. 8, pp. 978-984, 2012.

[139] L. G. Dias, A. P. Pereira, and L. M. Estevinho, "Comparative study of different Portuguese samples of propolis: pollinic, sensorial, physicochemical, microbiological characterization and antibacterial activity," Food and Chemical Toxicology, vol. 50, no. 12, pp. 4246-4253, 2012.

[140] S. I. Falcão, N. Vale, P. Cos et al., "In vitro evaluation of portuguese propolis and floral sources for antiprotozoal, antibacterial and antifungal activity," Phytotherapy Research, vol. 28, no. 3, pp. 437-443, 2014.

[141] C. Ota, C. Unterkircher, V. Fantinato, and M. T. Shimizu, "Antifungal activity of propolis on different species of Candida," Mycoses, vol. 44, no. 9-10, pp. 375-378, 2001.
[142] J. M. Murad, S. A. Calvi, A. M. V. C. Soares, V. Bankova, and J. M. Sforcin, "Effects of propolis from Brazil and Bulgaria on fungicidal activity of macrophages against Paracoccidioides brasiliensis," Journal of Ethnopharmacology, vol. 79, no. 3, pp. 331-334, 2002.

[143] A. B. S. Siqueira, B. S. Gomes, I. Cambuim et al., "Trichophyton species susceptibility to green and red propolis from Brazil," Letters in Applied Microbiology, vol. 48, no. 1, pp. 90-96, 2009.

[144] K. F. D. Dota, M. E. L. Consolaro, T. I. E. Svidzinski, and M. L. Bruschi, "Antifungal activity of brazilian propolis microparticles against yeasts isolated from vulvovaginal candidiasis," Evidence-Based Complementary and Alternative Medicine, vol. 2011, Article ID 201953, 8 pages, 2011.

[145] J. S. Bonvehí and A. L. Gutiérrez, "The antimicrobial effects of propolis collected in different regions in the Basque Country (Northern Spain)," World Journal of Microbiology and Biotechnology, vol. 28, no. 4, pp. 1351-1358, 2012.

[146] E. N. Quiroga, D. A. Sampietro, J. R. Soberón, M. A. Sgariglia, and M. A. Vattuone, "Propolis from the northwest of Argentina as a source of antifungal principles," Journal of Applied Microbiology, vol. 101, no. 1, pp. 103-110, 2006.

[147] P. Szweda, K. Gucwa, E. Kurzyk et al., "Essential oils, silver nanoparticles and propolis as alternative agents against fluconazole resistant Candida albicans, Candida glabrata and Candida krusei clinical isolates," Indian Journal of Microbiology, vol. 55, no. 2, pp. 175-183, 2015.

[148] B. Pippi, A. Lana, R. Moraes et al., "In vitro evaluation of the acquisition of resistance, antifungal activity and synergism of Brazilian red propolis with antifungal drugs on Candida spp," Journal of Applied Microbiology, vol. 118, no. 4, pp. 839-850, 2015.

[149] I. R. G. Capoci, P. de Souza Bonfim-Mendonça, G. S. Arita et al., "Propolis is an efficient fungicide and inhibitor of biofilm production by vaginal Candida albicans," Evidence-Based Complementary and Alternative Medicine, vol. 2015, Article ID 287693, 9 pages, 2015.

[150] A. A. Berretta, P. A. de Castro, A. H. Cavalheiro et al., "Evaluation of mucoadhesive gels with propolis (EPP-AF) in preclinical treatment of candidiasis vulvovaginal infection," Evidence-Based Complementary and Alternative Medicine, vol. 2013, Article ID 641480, 18 pages, 2013.

[151] P. A. De Castro, V. L. P. Bom, N. A. Brown et al., "Identification of the cell targets important for propolis-induced cell death in Candida albicans," Fungal Genetics and Biology, vol. 60, pp. 7486, 2013.

[152] D. Sawicka, H. Car, M. H. Borawska, and J. Nikliński, “The anticancer activity of propolis," Folia Histochemica et Cytobiologica, vol. 50, no. 1, pp. 25-37, 2012.

[153] J. R. Araújo, P. Gonçalves, and F. Martel, "Chemopreventive effect of dietary polyphenols in colorectal cancer cell lines," Nutrition Research, vol. 31, no. 2, pp. 77-87, 2011.

[154] R. Kubina, A. Kabała-Dzik, A. Dziedzic et al., “The ethanol extract of polish propolis exhibits anti-proliferative and/or proapoptotic effect on HCT 116 colon cancer and me 45 malignant melanoma cells in vitro conditions," Advances in Clinical and Experimental Medicine, vol. 24, no. 2, pp. 203-212, 2015.

[155] M. Ishihara, K. Naoi, M. Hashita, Y. Itoh, and M. Suzui, "Growth inhibitory activity of ethanol extracts of Chinese and Brazilian propolis in four human colon carcinoma cell lines," Oncology Reports, vol. 22, no. 2, pp. 349-354, 2009.

[156] S. M. Messerli, M.-R. Ahn, K. Kunimasa et al., "Artepillin C (ARC) in Brazilian green propolis selectively blocks oncogenic 
PAK1 signaling and suppresses the growth of NF tumors in mice," Phytotherapy Research, vol. 23, no. 3, pp. 423-427, 2009.

[157] S. Awale, F. Li, H. Onozuka, H. Esumi, Y. Tezuka, and S. Kadota, "Constituents of Brazilian red propolis and their preferential cytotoxic activity against human pancreatic PANC-1 cancer cell line in nutrient-deprived condition," Bioorganic \& Medicinal Chemistry, vol. 16, no. 1, pp. 181-189, 2008.

[158] H. Li, A. Kapur, J. X. Yang et al., "Antiproliferation of human prostate cancer cells by ethanolic extracts of Brazilian propolis and its botanical origin," International Journal of Oncology, vol. 31, no. 3, pp. 601-606, 2007.

[159] G. Ozturk, Z. Ginis, S. Akyol, G. Erden, A. Gurel, and O. Akyol, "The anticancer mechanism of caffeic acid phenethyl ester (CAPE): review of melanomas, lung and prostate cancers," European Review for Medical and Pharmacological Sciences, vol. 16, no. 15, pp. 2064-2068, 2012.

[160] Y.-J. He, B.-H. Liu, D.-B. Xiang, Z.-Y. Qiao, T. Fu, and Y.-H. $\mathrm{He}$, "Inhibitory effect of caffeic acid phenethyl ester on the growth of SW480 colorectal tumor cells involves $\beta$-catenin associated signaling pathway down-regulation," World Journal of Gastroenterology, vol. 12, no. 31, pp. 4981-4985, 2006.

[161] C.-P. Chuu, H.-P. Lin, M. F. Ciaccio et al., "Caffeic acid phenethyl ester suppresses the proliferation of human prostate cancer cells through inhibition of p70S6K and Akt signaling networks," Cancer Prevention Research, vol. 5, no. 5, pp. 788797, 2012.

[162] J. Wu, C. Omene, J. Karkoszka et al., "Caffeic acid phenethyl ester (CAPE), derived from a honeybee product propolis, exhibits a diversity of anti-tumor effects in pre-clinical models of human breast cancer," Cancer Letters, vol. 308, no. 1, pp. 4353, 2011.

[163] C. Omene, M. Kalac, J. Wu, E. Marchi, K. Frenkel, and O. A. O'Connor, "Propolis and its active component, caffeic acid phenethyl ester (CAPE), modulate breast cancer therapeutic targets via an epigenetically mediated mechanism of action," Journal of Cancer Science and Therapy, vol. 5, no. 10, pp. 334342, 2013.

[164] C. O. Omene, J. Wu, and K. Frenkel, "Caffeic Acid Phenethyl Ester (CAPE) derived from propolis, a honeybee product, inhibits growth of breast cancer stem cells," Investigational New Drugs, vol. 30, no. 4, pp. 1279-1288, 2012.

[165] A. M. Alizadeh, H. Afrouzan, N. Dinparast-Djadid et al., "Chemoprotection of MNNG-initiated gastric cancer in rats using Iranian propolis," Archives of Iranian Medicine, vol. 18, no. 1, pp. 18-23, 2015.

[166] E. Szliszka, Z. P. Czuba, J. Bronikowska, A. Mertas, A. Paradysz, and W. Krol, "Ethanolic extract of propolis augments TRAILinduced apoptotic death in prostate cancer cells," EvidenceBased Complementary and Alternative Medicine, vol. 2011, Article ID 535172, 11 pages, 2011.

[167] E. Szliszka, G. Zydowicz, B. Janoszka, C. Dobosz, G. KowalczykZiomek, and W. Krol, "Ethanolic extract of Brazilian green propolis sensitizes prostate cancer cells to TRAIL-induced apoptosis," International Journal of Oncology, vol. 38, no. 4, pp. 941-953, 2011.

[168] E. Szliszka and W. Krol, "Polyphenols isolated from propolis augment TRAIL-induced apoptosis in cancer cells," EvidenceBased Complementary and Alternative Medicine, vol. 2013, Article ID 731940, 10 pages, 2013.

[169] E. Szliszka, G. Zydowicz, E. Mizgala, and W. Krol, "Artepillin C (3,5-diprenyl-4-hydroxycinnamic acid) sensitizes LNCaP prostate cancer cells to TRAIL-induced apoptosis," International Journal of Oncology, vol. 41, no. 3, pp. 818-828, 2012.

[170] K. McEleny, R. Coffey, C. Morrissey, J. M. Fitzpatrick, and R. W. G. Watson, "Caffeic acid phenethyl ester-induced PC-3 cell apoptosis is caspase-dependent and mediated through the loss of inhibitors of apoptosis proteins," BJU International, vol. 94, no. 3, pp. 402-406, 2004.

[171] V. Cavaliere, D. L. Papademetrio, T. Lombardo, S. N. Costantino, G. A. Blanco, and E. M. C. Álvarez, "Caffeic acid phenylethyl ester and MG132, two novel nonconventional chemotherapeutic agents, induce apoptosis of human leukemic cells by disrupting mitochondrial function," Targeted Oncology, vol. 9, no. 1, pp. 25-42, 2014.

[172] K. W. Lee, N. J. Kang, J. H. Kim et al., "Caffeic acid phenethyl ester inhibits invasion and expression of matrix metalloproteinase in SK-Hep1 human hepatocellular carcinoma cells by targeting nuclear factor kappa B," Genes and Nutrition, vol. 2, no. 4, pp. 319-322, 2008.

[173] P. Saharinen, L. Eklund, K. Pulkki, P. Bono, and K. Alitalo, "VEGF and angiopoietin signaling in tumor angiogenesis and metastasis," Trends in Molecular Medicine, vol. 17, no. 7, pp. 347362, 2011.

[174] M.-R. Ahn, K. Kunimasa, T. Ohta et al., "Suppression of tumorinduced angiogenesis by Brazilian propolis: major component artepillin $\mathrm{C}$ inhibits in vitro tube formation and endothelial cell proliferation," Cancer Letters, vol. 252, no. 2, pp. 235-243, 2007.

[175] T. Ohta, K. Kunimasa, M.-R. Ahn et al., "Brazilian propolis suppresses angiogenesis by inducing apoptosis in tubeforming endothelial cells through inactivation of survival signal ERK1/2," Evidence-Based Complementary and Alternative Medicine, vol. 2011, Article ID 870753, 8 pages, 2011.

[176] S. S. Yun, E. H. Park, J. J. Kyung, and C. Jin, "Inhibition of angiogenesis by propolis," Archives of Pharmacal Research, vol. 25, no. 4, pp. 500-504, 2002.

[177] T. Ohta, K. Kunimasa, T. Kobayashi, M. Sakamoto, and K. Kaji, "Propolis suppresses tumor angiogenesis by inducing apoptosis in tube-forming endothelial cells," Bioscience, Biotechnology and Biochemistry, vol. 72, no. 9, pp. 2436-2440, 2008.

[178] M. Keshavarz, A. Mostafaie, K. Mansouri, Y. Shakiba, and H. R. M. Motlagh, "Inhibition of corneal neovascularization with propolis extract," Archives of Medical Research, vol. 40, no. 1, pp. 59-61, 2009.

[179] H. Izuta, M. Shimazawa, K. Tsuruma, Y. Araki, S. Mishima, and H. Hara, "Bee products prevent VEGF-induced angiogenesis in human umbilical vein endothelial cells," BMC Complementary and Alternative Medicine, vol. 9, article 45, 2009.

[180] V. A. Isidorov, L. Szczepaniak, and S. Bakier, "Rapid GC/MS determination of botanical precursors of eurasian propolis," Food Chemistry, vol. 142, pp. 101-106, 2014.

[181] S. D. Leonhardt, H. M. Wallace, and T. Schmitt, “The cuticular profiles of Australian stingless bees are shaped by resin of the eucalypt tree Corymbia torelliana," Austral Ecology, vol. 36, no. 5, pp. 537-543, 2011.

[182] R. Christov, V. Bankova, I. Tsvetkova, A. Kujumgiev, and A. Delgado Tejera, "Antibacterial furofuran lignans from Canary Islands propolis," Fitoterapia, vol. 70, no. 1, pp. 89-92, 1999.

[183] J. F. Campos, U. P. dos Santos, L. F. B. Macorini et al., "Antimicrobial, antioxidant and cytotoxic activities of propolis from Melipona orbignyi (Hymenoptera, Apidae)," Food and Chemical Toxicology, vol. 65, pp. 374-380, 2014. 
[184] A. Mavri, H. Abramovič, T. Polak et al., "Chemical properties and antioxidant and antimicrobial activities of Slovenian propolis," Chemistry and Biodiversity, vol. 9, no. 8, pp. 1545-1558, 2012.

[185] A. A. Lopes, T. S. Ferreira, R. T. Nesi et al., "Antioxidant action of propolis on mouse lungs exposed to short-term cigarette smoke," Bioorganic and Medicinal Chemistry, vol. 21, no. 24, pp. 7570-7577, 2013.

[186] Y. Aliyazicioglu, S. Demir, I. Turan et al., "Preventive and protective effects of turkish propolis on $\mathrm{H}_{2} \mathrm{O}_{2}$-induced DNA damage in foreskin fibroblast cell lines," Acta Biologica Hungarica, vol. 62, no. 4, pp. 388-396, 2011.

[187] M. E. Yonar, S. M. Yonar, M. S. Ural, S. Silici, and M. Dusukcan, "Protective role of propolis in chlorpyrifos-induced changes in the haematological parameters and the oxidative/antioxidative status of Cyprinus carpio carpio," Food and Chemical Toxicology, vol. 50, no. 8, pp. 2703-2708, 2012.

[188] N. Oršolić, D. Sirovina, G. Gajski, V. Garaj-Vrhovac, M. Jazvinšćak Jembrek, and I. Kosalec, "Assessment of DNA damage and lipid peroxidation in diabetic mice: effects of propolis and epigallocatechin gallate (EGCG)," Mutation Research, vol. 757, no. 1, pp. 36-44, 2013.

[189] A. Rossi, R. Longo, A. Russo, F. Borrelli, and L. Sautebin, "The role of the phenethyl ester of caffeic acid (CAPE) in the inhibition of rat lung cyclooxygenase activity by propolis," Fitoterapia, vol. 73, supplement 1, pp. S30-S37, 2002.

[190] O. Koksel, A. Ozdulger, L. Tamer et al., "Effects of caffeic acid phenethyl ester on lipopolysaccharide-induced lung injury in rats," Pulmonary Pharmacology and Therapeutics, vol. 19, no. 2, pp. 90-95, 2006.

[191] M. M. M. Abdel-Latif, H. J. Windle, B. S. El Homasany, K. Sabra, and D. Kelleher, "Caffeic acid phenethyl ester modulates Helicobacter pylori-induced nuclear factor-kappa B and activator protein-1 expression in gastric epithelial cells," British Journal of Pharmacology, vol. 146, no. 8, pp. 1139-1147, 2005.

[192] F. Missima, A. C. Pagliarone, C. L. Orsatti, J. P. Araújo Jr., and J. M. Sforcin, "The Effect of propolis on Th1/Th2 cytokine expression and production by melanoma-bearing mice submitted to stress," Phytotherapy Research, vol. 24, no. 10, pp. 1501-1507, 2010.

[193] B. J. Conti, M. C. Búfalo, M. D. A. Golim, V. Bankova, and J. M. Sforcin, "Cinnamic acid is partially involved in propolis immunomodulatory action on human monocytes," Evidencebased Complementary and Alternative Medicine, vol. 2013, Article ID 109864, 7 pages, 2013.

[194] G. Girgin, T. Baydar, M. Ledochowski et al., "Immunomodulatory effects of Turkish propolis: changes in neopterin release and tryptophan degradation," Immunobiology, vol. 214, no. 2, pp. 129-134, 2009.

[195] J. H. Park, J. K. Lee, H. S. Kim et al., "Immunomodulatory effect of caffeic acid phenethyl ester in Balb/c mice," International Immunopharmacology, vol. 4, no. 3, pp. 429-436, 2004.

[196] S. Nolkemper, J. Reichling, K. H. Sensch, and P. Schnitzler, "Mechanism of herpes simplex virus type 2 suppression by propolis extracts," Phytomedicine, vol. 17, no. 2, pp. 132-138, 2010.

[197] V. Bankova, A. Galabov, D. Antonova, N. Vilhelmova, and B. Di Perri, "Chemical composition of Propolis Extract ACF and activity against herpes simplex virus," Phytomedicine, vol. 21, no. 11, pp. 1432-1438, 2014.

[198] K. Kuwata, T. Takemura, T. Urushisaki et al., "3,4dicaffeoylquinic acid, a major constituent of Brazilian propolis, increases TRAIL expression and extends the lifetimes of mice infected with the influenza a virus," Evidence-Based Complementary and Alternative Medicine, vol. 2012, Article ID 946867, 7 pages, 2012.

[199] M. P. Popova, I. B. Chinou, I. N. Marekov, and V. S. Bankova, "Terpenes with antimicrobial activity from Cretan propolis," Phytochemistry, vol. 70, no. 10, pp. 1262-1271, 2009.

[200] H. F. Santana, A. A. T. Barbosa, S. O. Ferreira, and H. C. Mantovani, "Bactericidal activity of ethanolic extracts of propolis against Staphylococcus aureus isolated from mastitic cows," World Journal of Microbiology and Biotechnology, vol. 28, no. 2, pp. 485-491, 2012.

[201] L. Netíková, P. Bogusch, and P. Heneberg, "Czech ethanolfree propolis extract displays inhibitory activity against a broad spectrum of bacterial and fungal pathogens," Journal of Food Science, vol. 78, no. 9, pp. M1421-M1429, 2013.

[202] R. D. O. Orsi, J. M. Sforcin, S. R. Cunha Funari, A. Fernandes Jr., and V. Bankova, "Synergistic effect of propolis and antibiotics on the Salmonella typhi," Brazilian Journal of Microbiology, vol. 37, no. 2, pp. 108-112, 2006.

[203] R. O. Orsi, J. M. Sforcin, S. R. C. Funari, and V. Bankova, "Effects of Brazilian and Bulgarian propolis on bactericidal activity of macrophages against Salmonella Typhimurium," International Immunopharmacology, vol. 5, no. 2, pp. 359-368, 2005.

[204] Z. Yildirim, S. Hacievliyagil, N. O. Kutlu et al., "Effect of water extract of Turkish propolis on tuberculosis infection in guineapigs," Pharmacological Research, vol. 49, no. 3, pp. 287-292, 2004.

[205] A. R. Khosravi, H. Shokri, D. Nikaein et al., "Yeasts as important agents of onychomycosis: in vitro activity of propolis against yeasts isolated from patients with nail infection," Journal of Alternative and Complementary Medicine, vol. 19, no. 1, pp. 5762, 2013.

[206] H. C. Kuo, W. H. Kuo, Y. J. Lee, W. L. Lin, F. P. Chou, and T. H. Tseng, "Inhibitory effect of caffeic acid phenethyl ester on the growth of C6 glioma cells in vitro and in vivo," Cancer Letters, vol. 234, no. 2, pp. 199-208, 2006.

[207] Y.-J. Chen, M.-S. Shiao, M.-L. Hsu, T.-H. Tsai, and S.-Y. Wang, "Effect of caffeic acid phenethyl ester, an antioxidant from propolis, on inducing apoptosis in human leukemic HL-60 cells," Journal of Agricultural and Food Chemistry, vol. 49, no. 11, pp. 5615-5619, 2001.

[208] Y. Akao, H. Maruyama, K. Matsumoto et al., "Cell growth inhibitory effect of cinnamic acid derivatives from propolis on human tumor cell lines," Biological and Pharmaceutical Bulletin, vol. 26, no. 7, pp. 1057-1059, 2003.

[209] H. Hattori, K. Okuda, T. Murase et al., "Isolation, identification, and biological evaluation of HIF-1-modulating compounds from Brazilian green propolis," Bioorganic and Medicinal Chemistry, vol. 19, no. 18, pp. 5392-5401, 2011.

[210] C. A. Dornelas, F. V. Fechine-Jamacaru, I. L. Albuquerque et al., "Angiogenesis inhibition by green propolis and the angiogenic effect of L-lysine on bladder cancer in rats," Acta Cirurgica Brasileira, vol. 27, no. 8, pp. 529-536, 2012.

[211] J. B. Daleprane, T. Schmid, N. Dehne et al., "Suppression of hypoxia-inducible factor- $1 \alpha$ contributes to the antiangiogenic activity of red propolis polyphenols in human endothelial cells," Journal of Nutrition, vol. 142, no. 3, pp. 441-447, 2012.

[212] T. Kamiya, H. Nishihara, H. Hara, and T. Adachi, "Ethanol extract of Brazilian red propolis induces apoptosis in human breast cancer MCF-7 cells through endoplasmic reticulum 
stress," Journal of Agricultural and Food Chemistry, vol. 60, no. 44, pp. 11065-11070, 2012.

[213] H.-P. Lin, S. S. Jiang, and C.-P. Chuu, "Caffeic acid phenethyl ester causes $\mathrm{p} 21^{\mathrm{CIP1}}$ induction, Akt signaling reduction, and growth inhibition in PC-3 human prostate cancer cells," PLoS ONE, vol. 7, no. 2, Article ID e31286, 2012.

[214] Y.-Y. Kuo, H.-P. Lin, C. Huo et al., "Caffeic acid phenethyl ester suppresses proliferation and survival of TW2.6 human oral cancer cells via inhibition of akt signaling," International Journal of Molecular Sciences, vol. 14, no. 5, pp. 8801-8817, 2013.

[215] H. J. Hwang, H. J. Park, H.-J. Chung et al., "Inhibitory effects of caffeic acid phenethyl ester on cancer cell metastasis mediated by the down-regulation of matrix metalloproteinase expression in human HT1080 fibrosarcoma cells," Journal of Nutritional Biochemistry, vol. 17, no. 5, pp. 356-362, 2006.

[216] H. Seda Vatansever, K. Sorkun, S. Ismet Deliloĝlu Gurhan et al., "Propolis from Turkey induces apoptosis through activating caspases in human breast carcinoma cell lines," Acta Histochemica, vol. 112, no. 6, pp. 546-556, 2010.

[217] M. Watabe, K. Hishikawa, A. Takayanagi, N. Shimizu, and T. Nakaki, "Caffeic acid phenethyl ester induces apoptosis by inhibition of NFkappaB and activation of Fas in human breast cancer MCF-7 cells," The Journal of Biological Chemistry, vol. 279, no. 7, pp. 6017-6026, 2004.

[218] I. Valença, F. Morais-Santos, V. Miranda-Gonçalves, A. M. Ferreira, C. Almeida-Aguiar, and F. Baltazar, "Portuguese propolis disturbs glycolytic metabolism of human colorectal cancer in vitro," BMC Complementary and Alternative Medicine, vol. 13, article 184, 2013. 


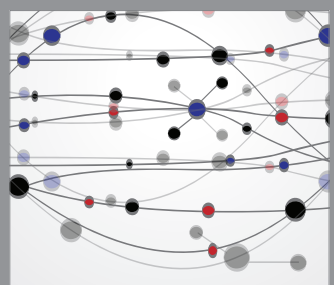

The Scientific World Journal
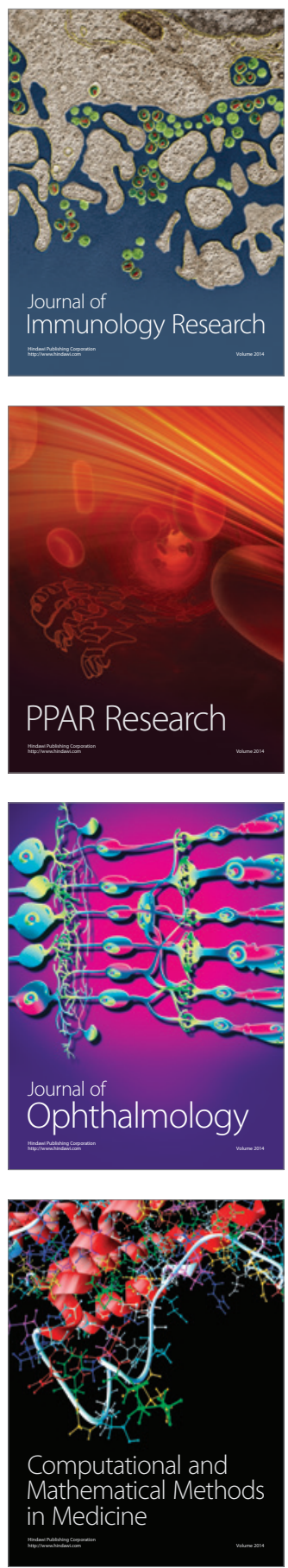

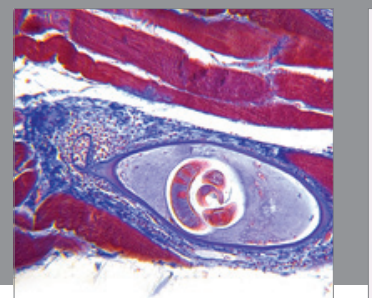

Gastroenterology

Research and Practice
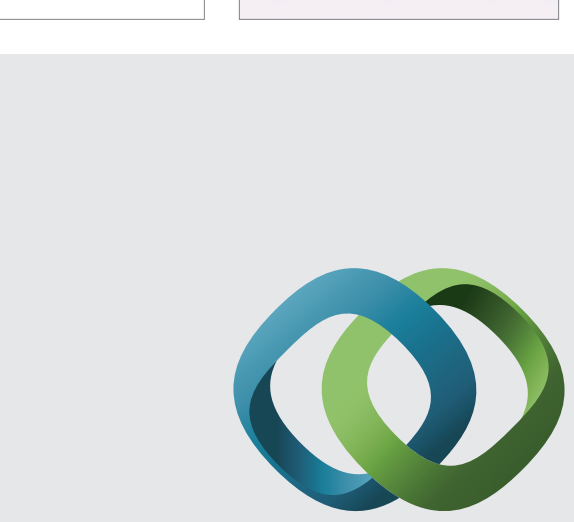

\section{Hindawi}

Submit your manuscripts at

http://www.hindawi.com
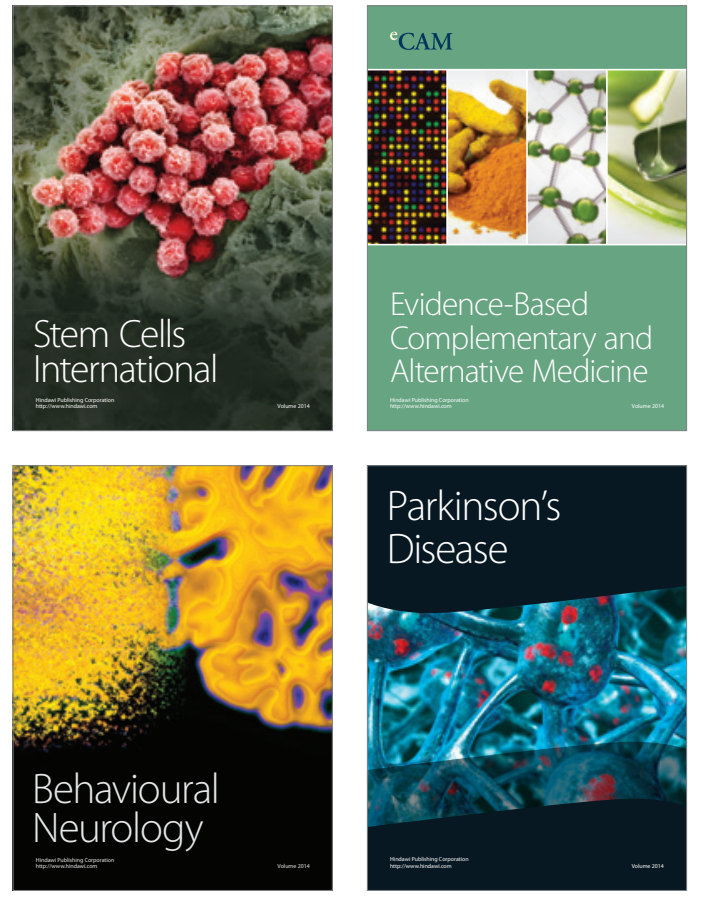
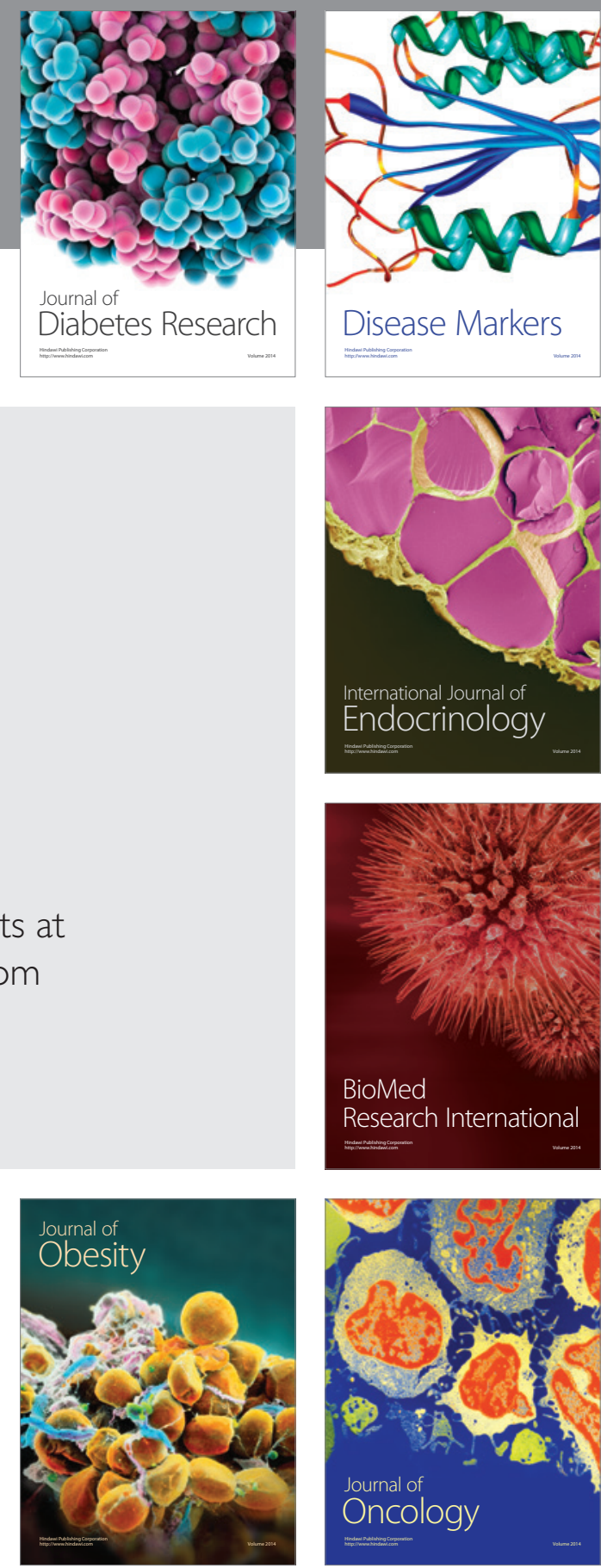

Disease Markers
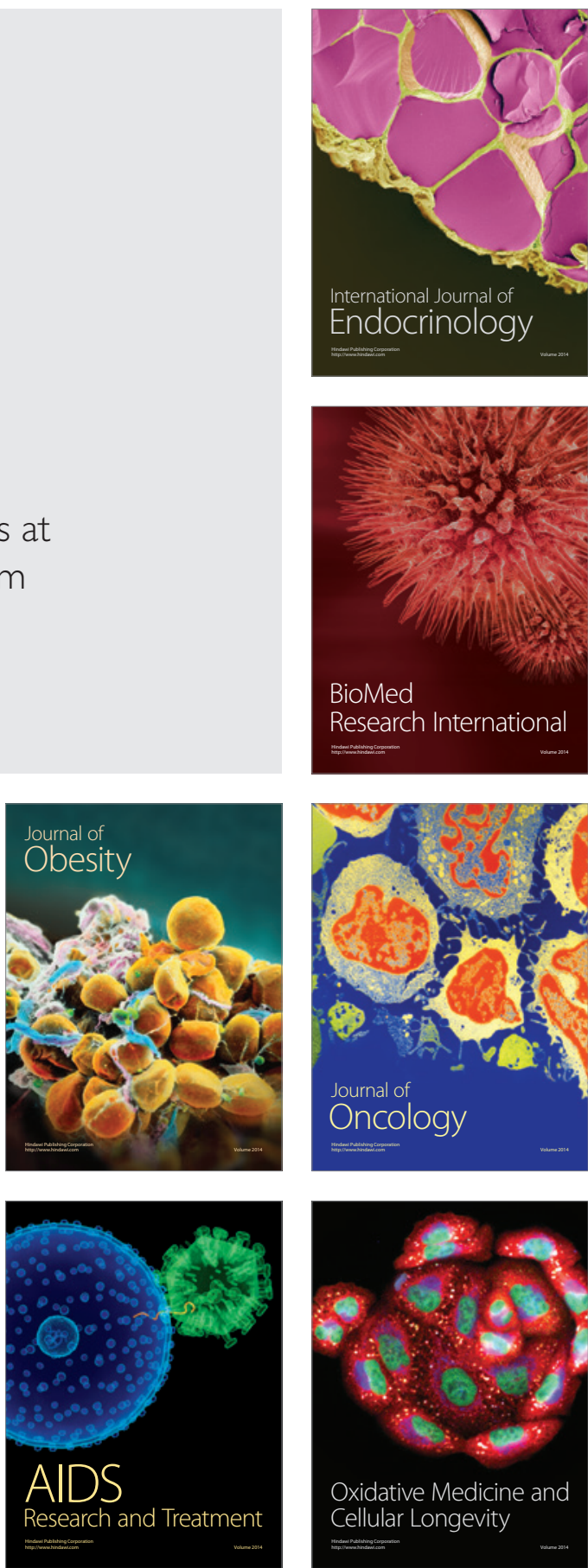